\title{
Experimental Characterization of Three-Dimensional Scramjet Inlet with Variable Internal Contraction
}

\author{
Oliver M. Hohn*® and Ali Gülhan \\ DLR, German Aerospace Center, 51147 Cologne, Germany \\ https://doi.org/10.2514/1.B38315
}

\begin{abstract}
A compact three-dimensional scramjet intake with a high compression ratio and a movable cowl as a starting device and for the adaption of the internal contraction to respective operating conditions was designed for a parabolic reentry flight experiment. In an extensive measurement campaign, conducted in a blowdown wind tunnel at Mach 7, the operational behavior of this inlet was characterized. The parameters investigated include internal contraction ratio, Reynolds number, angle of attack, and angle of yaw, and the starting behavior was examined. Static and total pressure ratios and mass capture ratios were used to evaluate the performance of the inlet and throttle curves to determine the operational limits. The flowfield was studied by schlieren images, wall pressure distributions, and Mach number profiles in the interface of the isolator and combustion chamber, which were determined with a pressure measurement rake with static and pitot pressure probes. The flow on the external ramp was analyzed by infrared thermography. The inlet showed good performance regarding compression and efficiency and proved to be quite robust at various flight angles. The performance tended to improve, and the inlet operated more stably with increasing internal contraction, with the most important factor being whether the inlet leading-edge shock was captured by the cowl.
\end{abstract}

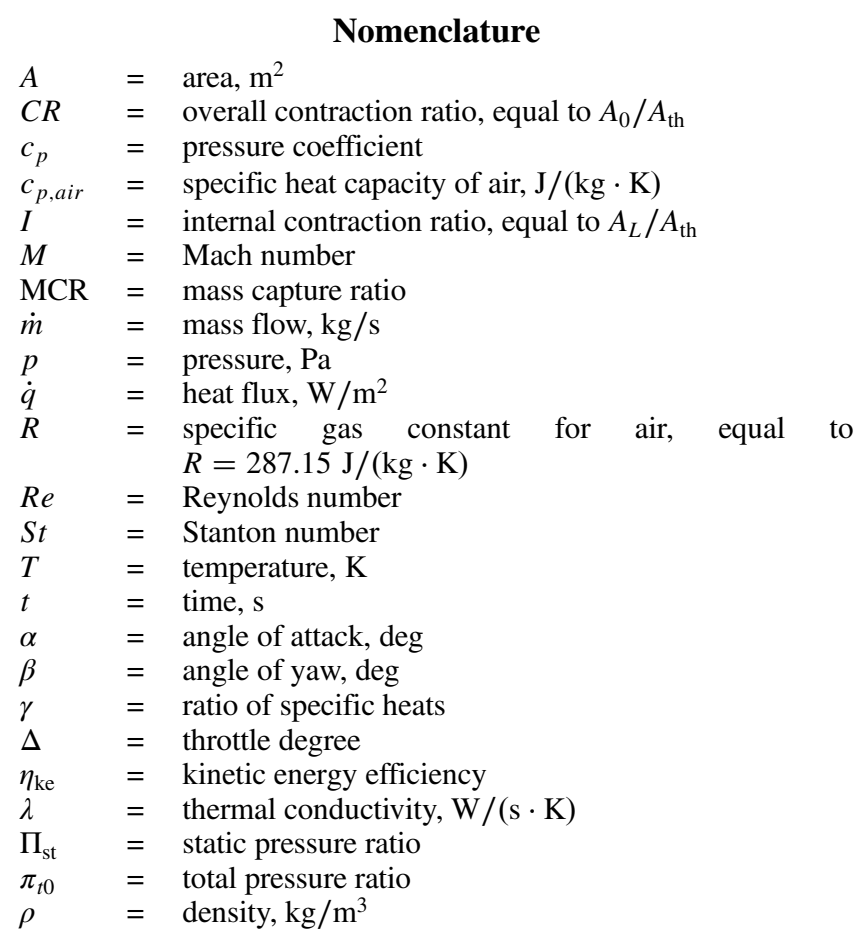

Presented as Paper 2012-5975 at the 18th AIAA/3AF International Space Planes and Hypersonic Systems and Technologies Conference, Tours, France, September 24-28, 2012; received 11 November 2020; revision received 7 May 2021; accepted for publication 18 July 2021; published online Open Access 28 September 2021. Copyright $\odot 2021$ by Oliver M. Hohn. Published by the American Institute of Aeronautics and Astronautics, Inc., with permission. All requests for copying and permission to reprint should be submitted to CCC at www.copyright.com; employ the eISSN 1533-3876 to initiate your request. See also AIAA Rights and Permissions www.aiaa.org/randp.

*Postdoctoral Research Associate, Supersonic and Hypersonic Technologies Department, Institute of Aerodynamics and Flow Technology, Linder Höhe. Member AIAA.

†Head of Department, Supersonic and Hypersonic Technologies Department, Institute of Aerodynamics and Flow Technology, Linder Höhe. Member AIAA.

\begin{tabular}{|c|c|c|}
\hline \multicolumn{3}{|c|}{ Subscripts } \\
\hline$c$ & $=$ & capture area \\
\hline ex & $=$ & isolator exit \\
\hline$L$ & $=$ & $\operatorname{lip}$ \\
\hline st & $=$ & static \\
\hline th & $=$ & throat \\
\hline$t 0$ & $=$ & wind-tunnel total conditions \\
\hline$\infty$ & $=$ & wind-tunnel freestream conditions \\
\hline
\end{tabular}

\section{Introduction}

Q CRAMJETS have been a focus in the development of advanced high-speed propulsion systems for several decades $[1,2]$. In recent years, advances in flight testing have sparked a renewed interest in this field of science and triggered several new research

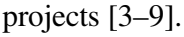

Two key features of a scramjet propulsion system are that compression of the flow to reach the conditions required in the combustion chamber is achieved merely by decelerating the flow in the inlet without any mechanical compression system and that combustion takes place at supersonic speeds [1]. This poses strong requirements on the inlet design as it has to supply a sufficient mass flow of air at conditions required for supersonic combustion and thus makes it a critical system component. The quality at which the inlet fulfills this task is crucial to the overall scramjet performance [10].

Former research mostly focused on two-dimensional inlets $[3, \underline{6}, 11,12]$. Although three-dimensional (3D) inlets have been researched in the past $[10,13]$, only recently a stronger focus on $3 \mathrm{D}$ configurations was established. Heiser and Pratt [1] list several advantages of three-dimensional designs. Compression in both vertical and horizontal planes allows for a more compact and lighter design. Ramp angles can be smaller, resulting in weaker shocks, lower total pressure losses, and less shock-induced incipient separation. Furthermore advances in design techniques such as streamline tracing [14,15] enable more possibilities regarding the engine configuration.

The inlet in this paper was designed for a flight experiment with parabolic reentry where scramjet operation is achieved during reentry in a corridor between 30 and $25 \mathrm{~km}$ altitude at flight Mach numbers between 7 and $8[\underline{8}, 16]$. For the proposed configuration, the intake design had to comply with several prerequisites. Potential launcher systems for the flight experiment limit the size of the overall configuration and thus require a very compact inlet design. Despite this, as there should be no forebody and consequently all of the compression has to take place in the inlet, it needs to have a high static pressure 
ratio of $\Pi_{\mathrm{st}} \approx 40-45$ (and correspondingly large contraction $8 \leq C R \leq 8.5$ ), to achieve the requirements for supersonic combustion ( $p_{\text {st }} \approx 50 \mathrm{kPa}$ and $T_{\text {st }} \approx 1000 \mathrm{~K}$ ) [3,, 17$]$. A central strut injector and staged combustion should be used, resulting in a rather narrow and high combustion chamber (65 mm wide and $40 \mathrm{~mm}$ high) [18]. Furthermore, as opposed to previous flight experiments [3], the intake should not have any bleed flow to reduce system complexity.

Considering all these requirements, a three-dimensional inlet with a single ramp and straight converging sidewalls was found best suited for this task [19]. Streamline-traced designs, for example, based on a Busemann flowfield or a rectangular-to-ellipticial-shape-transition (REST)-type inlet with adequate performance, would need to be significantly larger [19]. Also, two-dimensional inlets within the size limits were not capable of achieving sufficient compression [20]. Furthermore, previous investigations showed that enhancing the compression of a two-dimensional (2D) inlet with additional sidewall compression can cause severe implications on the inlet operation and performance [21]. In this case, the corner flow, induced by the interaction of ramp and sidewall shocks and the resulting complex flow structure with multiple shock-shock and shock-boundary layer interactions and strong vortices, as described by Goonko et al. [22] or Nguyen et al. [23], strongly impaired the starting behavior and also reduced the inlet efficiency. However, also for the present design, particular attention had to be attributed to the corner flow. Especially to reduce corner vortices, radii were applied to the corners of the entire flowpath, which had only negligible effect on the performance but significantly decreased vortices and produced a much more homogeneous flowfield [19].

To achieve shock-on-lip condition and thus minimize spillage and consequent losses, geometrical constraints require an internal contraction significantly above the Kantrowitz criterion [24] for the selfstarting of inlets. While experience shows that this limit applies well for 2D inlets, it is very conservative for 3D intakes, which usually have superior starting behavior $[10,17,19,25-27]$. However, other studies [28] and previous investigations showed that in some cases 2D inlets can be started above the Kantrowitz limit, while configurations with sidewall compression exhibited inferior performance and that starting was very dependent on local flow phenomena [21]. This suggests that inlet starting might be problematic in its design configuration. Thus, to achieve optimal inlet performance, a movable cowl as a starting mechanism was integrated. It also gives the opportunity to test the inlet at different internal contraction ratios and adapt it to off-design conditions such as angle of attack and Mach number variation.

This paper presents further results of an extensive measurement campaign to characterize the operational behavior and flowfield of this inlet, which was already reported on previously [29]. It was performed at $M=7$ at two flow conditions to analyze the Reynolds number influence which simulates different flight altitudes. The influence of the internal contraction was investigated, and the critical internal contraction for inlet starting was determined. The intake behavior was examined for angles of attack up to \pm 6 deg and angles of yaw up to $6 \mathrm{deg}$. The flowfield and performance were assessed by wall pressure measurements and a pressure rake with pitot and static pressure probes at the interface of isolator and combustion chamber. Stanton number distributions on the external ramp were evaluated by IR thermography, and schlieren images of the external flowfield and the internal flow in the isolator were recorded.

\section{Experimental Setup}

\section{A. Wind-Tunnel and Test Conditions}

Experiments were conducted in a hypersonic blow down wind tunnel that uses contoured axisymmetric nozzles with $600 \mathrm{~mm}$ exit diameter for fixed Mach numbers of 5.3, 6, 7, 8.7, and 11.2 for Reynolds numbers in the range of $2.5-20 \times 10^{6} \mathrm{~m}^{-1}$, with total pressures up to $4 \mathrm{MPa}$, total temperatures up to $1000 \mathrm{~K}$, and test durations up to $35 \mathrm{~s}$ [30]. Variation of total temperatures also allows us to obtain different wall temperature ratios $T_{w} / T_{t 0}$. Sketches of the wind tunnel and its performance map are shown in Figs. 1 and 2.

The test conditions in Table 1 were chosen for Reynolds number similarity of Mach 7 flights of a full-scale model at altitudes of $30 \mathrm{~km}$ (condition 1) and $25 \mathrm{~km}$ (condition 2). A total temperature of $700 \mathrm{~K}$

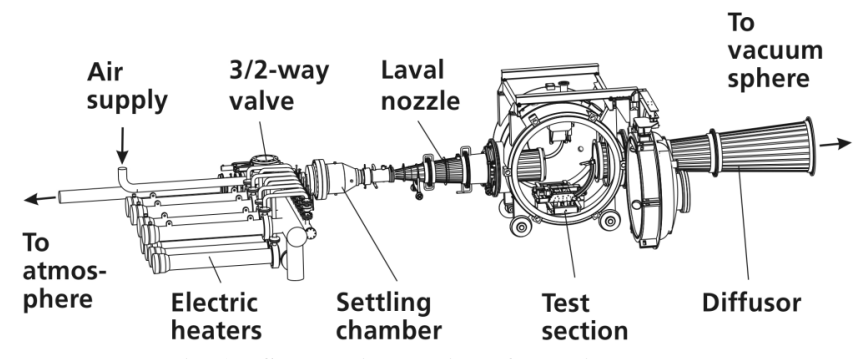

Fig. 1 Schematic drawing of the wind tunnel.

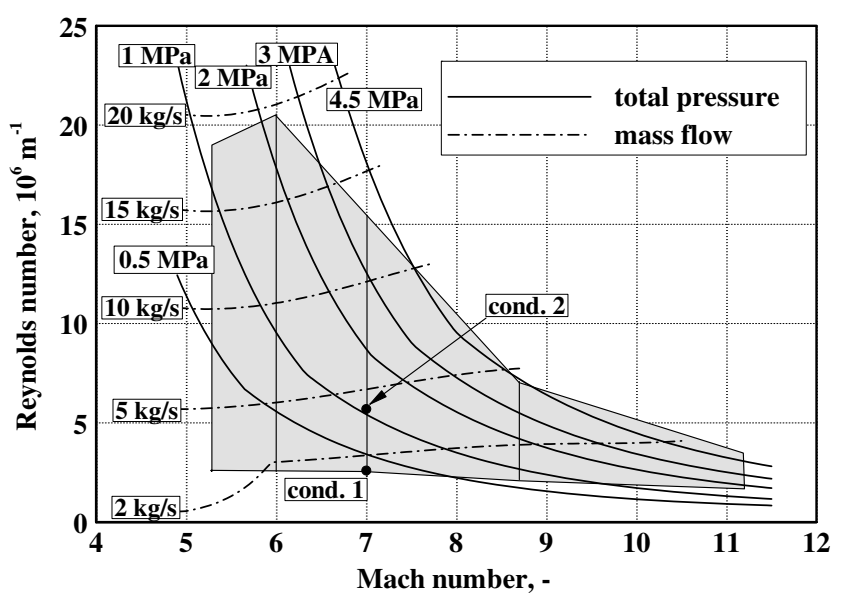

Fig. 2 Wind-tunnel performance map.

Table 1 Wind-tunnel conditions

\begin{tabular}{lcc}
\hline \hline Flow parameter & Condition 1 & Condition 2 \\
\hline$M_{\infty},-$ & $7.008 \pm 0.04$ & $7.052 \pm 0.04$ \\
$T_{t 0}, \mathrm{~K}$ & $700 \pm 11$ & $700 \pm 11$ \\
$p_{t 0}, \mathrm{kPa}$ & $790 \pm 8$ & $1750 \pm 20$ \\
$p_{\infty}, \mathrm{Pa}$ & $191 \pm 3$ & $423 \pm 8$ \\
$T_{\infty}, \mathrm{K}$ & $64.8 \pm 1$ & $64.8 \pm 1$ \\
$R e_{\infty, m}, 10^{6} \mathrm{~m}^{-1}$ & $2.6 \pm 0.1$ & $5.7 \pm 0.2$ \\
\hline \hline
\end{tabular}

and ambient temperature $(300 \mathrm{~K})$ for the model give a wall temperature ratio of $T_{w} / T_{t 0}=0.43$, which is considered sufficiently close to the real flight case with $T_{w} / T_{t 0} \approx 0.33$ when assuming a wall temperature in flight of $800 \mathrm{~K}$.

The uncertainties in Table 1 give the range of deviations of these parameters in the experiments. The actual freestream Mach number in the experiments accounting for the Reynolds number influence on the boundary layer in the nozzle is given by the empirical relation in Eq. (1):

$$
M=6.9711+1.4464 \times 10^{-2} R e-3.1125 \times 10^{-4} R e^{2}
$$

The Mach number varies less than $0.5 \%$ over the cross-section of the core flow as shown in Fig. 3. Equation (1) and the flow uniformity in Fig. 3 were determined by calibration measurements with pitot and static pressure probes [30]. Total temperature variation in the tests was about $\Delta T_{t 0}= \pm 11 \mathrm{~K}$ or $1.6 \%$ and for total pressure about $\Delta p_{t 0}=$ $\pm 8 \mathrm{kPa}$ or $1 \%$ for condition 1 and $\Delta p_{t 0}= \pm 20 \mathrm{kPa}$ or $1.1 \%$ for condition 2.

\section{B. Inlet Model}

The inlet features a single ramp with an $8 \mathrm{deg}$ ramp angle and converging sidewalls with angles of $7 \mathrm{deg}$ each for a total sidewall convergence of $14 \mathrm{deg}$. To reduce the complex corner flow, the corners have been rounded. Figure 4 shows schematic sketches of the inlet. Overall, the model is $75 \overline{0} \mathrm{~mm}$ long, with the defined 


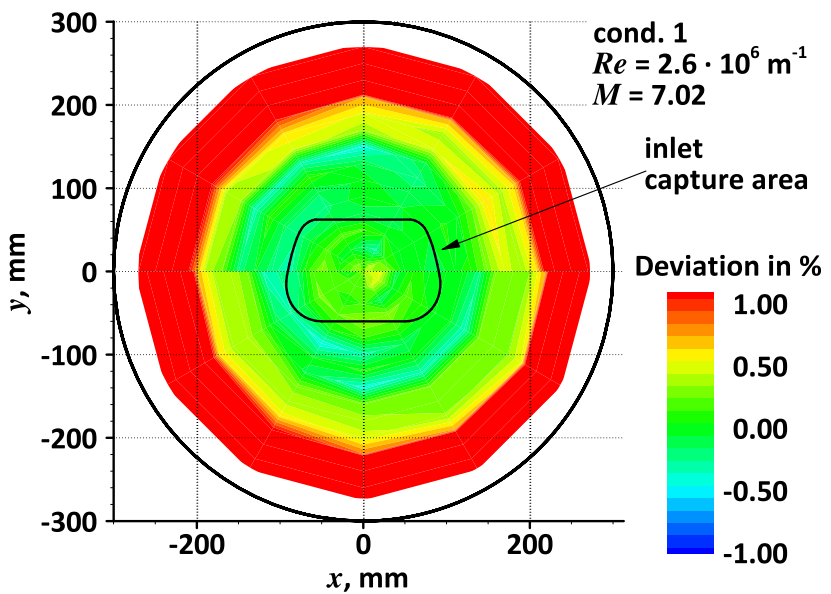

Fig. 3 Flow uniformity over nozzle exit.

interface of inlet/isolator and combustion chamber at $x=650 \mathrm{~mm}$. Downstream, the top and bottom walls are divergent by 1 deg each. The fixed part of the cowl starts at $550 \mathrm{~mm}$ with a leading edge angle of $3 \mathrm{deg}$. The design methodology is described in [19].

The movable cowl can be shifted by $\Delta x_{L}=150 \mathrm{~mm}$, varying the lip position from $x_{L}=390$ to $540 \mathrm{~mm}$, as indicated in the top and cut views. By moving the cowl, the internal contraction ratio can be modified in the range $1.3 \leq I \leq 2.62$ as Fig. 5 and Table 2 show and Sec. IV.A in relation to common starting limits. The design point for the shock-on-lip condition is $x_{L}=420 \mathrm{~mm}$ with an internal contraction of $I=2.28$. For $x_{L}<420 \mathrm{~mm}$, the ramp shock goes underneath the cowl, while for $x_{L} \geq 420 \mathrm{~mm}$, the ramp shock misses the cowl and causes some spillage. The lip of the cowl is V shaped in order to best adapt to the structures of ramp and sidewall shocks. The capture area of the inlet is $A_{\text {ref }}=0.0205 \mathrm{~m}^{2}$. The throat area at the interface of inlet and combustion chamber is $A_{\mathrm{th}}=2.51 \times 10^{-3} \mathrm{~m}^{2}$, giving an overall contraction ratio $C R=A_{\text {ref }} / A_{\text {th }}=8.12$.

In the experiments, the inlet is mounted to a conical throttle, which is used to simulate the combustion chamber backpressure. The throttling of the flow is expressed by the throttle degree $\Delta=$ $\left(A_{4} / A_{c}\right)$, where $A_{c}$ is the reference capture area of the inlet and $A_{4}$ the smallest cross-section of the throttle. At the start of the wind tunnel, the inlet is in its starting configuration with the cowl in the most downstream position and the throttle fully opened. After the wind tunnel is started and the inlet flow is established, the cowl is moved to its target position, and a throttle curve is recorded; in other words, the plug is continuously moved upstream, increasing the

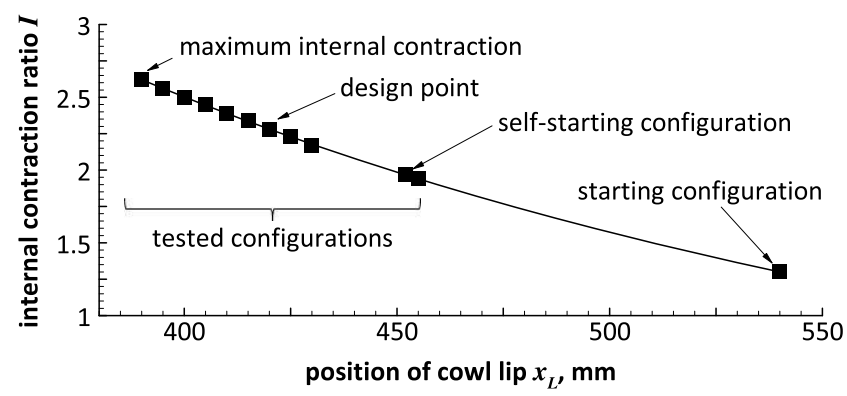

Fig. 5 Relation of internal contraction and lip position.

Table 2 Relation of internal contraction and lip position

\begin{tabular}{ll}
\hline \hline$x_{L}, \mathrm{~mm}$ & \multicolumn{1}{c}{$I$} \\
\hline 390 & 2.62 \\
400 & 2.5 \\
410 & 2.39 \\
420 & 2.28 \\
430 & 2.17 \\
452 & 1.97 \\
540 & 1.3 \\
\hline \hline
\end{tabular}

backpressure in the isolator up to the point of inlet unstart. Thus, we can see how the inlet and its flowfield behave at different backpressures and determine the operational range for each configuration, in other words, the maximum backpressure at which the inlet chokes. For tests with angle of attack, the inlet was moved to the desired angle after starting the wind tunnel and moving the cowl to its target position. For the angle of yaw, the angle was set up manually before the test run. It should be noted that this can impact the results, as previous investigations showed that hysteresis effects can occur [31].

\section{Measurement Techniques}

This section gives an overview of applied measurement techniques and their accuracies, which were estimated using the Gaussian error propagation rule according to Kirchner [32] with the accuracy of flow parameters listed in Table 1 as well as the accuracy of the respective sensors as input parameters [19].

\section{A. Pressure Measurements and Mach Number Calculation}

The inlet model is equipped with 55 wall pressure ports: 30 along the centerline of the lower wall, 9 on the fixed part of the upper wall, and 4
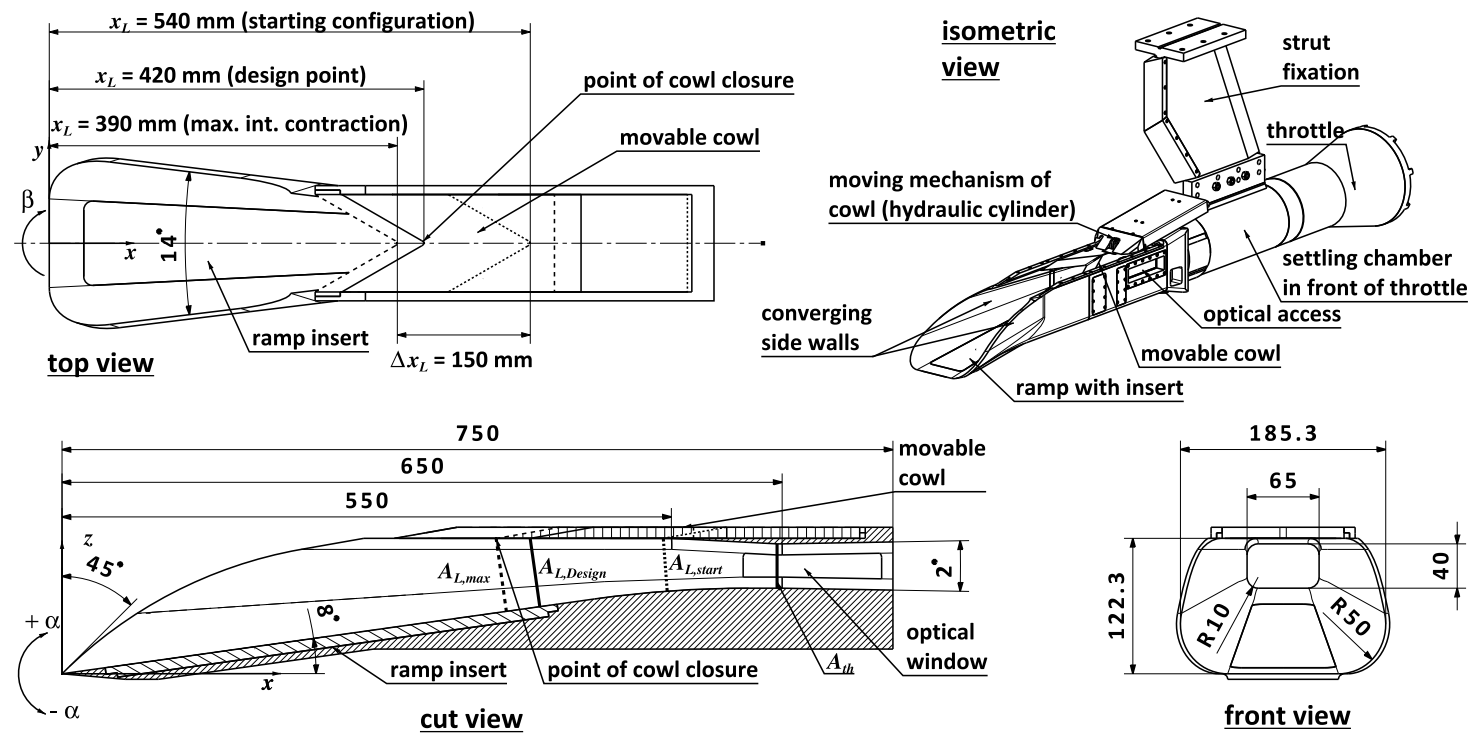

Fig. 4 Schematic drawings of the inlet model (max. = maximum; int. = internal). 


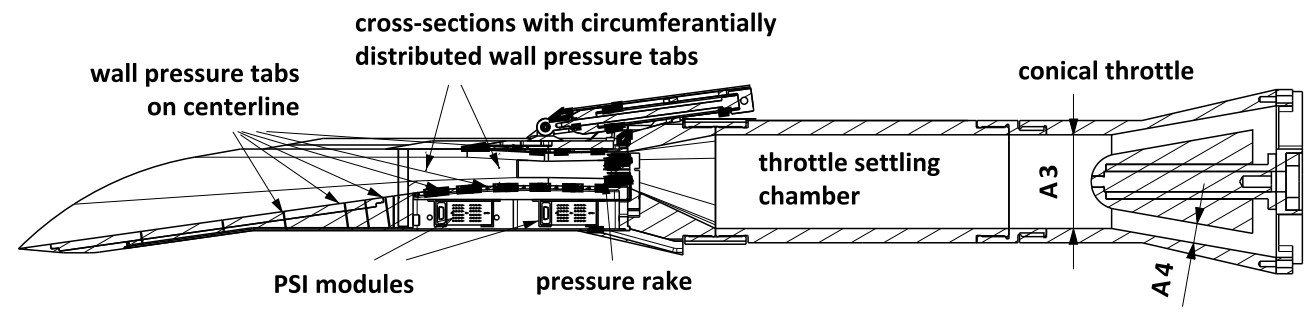

Fig. 6 Distribution of pressure measurement ports.

on the moveable cowl. Furthermore, there are two cross-sections, at $x=500 \mathrm{~mm}$ and $x=590 \mathrm{~mm}$ with circumferential distribution of six pressure ports each. The locations of the wall pressure ports are displayed in Fig. 6. In Sec. IV, wall pressure distributions are presented as pressure coefficients $c_{p}=\left(p-p_{\infty}\right) / q_{\infty}$.

A cross-shaped pressure measurement rake, shown in Fig. 7, was used to measure pitot and static pressure distributions at the downstream end of the inlet (at $x=720 \mathrm{~mm}$ ). From these measurements, Mach number profiles were determined from the ratio of static and pitot pressure [33] as well as the performance parameters described in the next section. The pitot and static pressure probes in the rake are arranged alternatingly as illustrated in Fig. 7. Over the isolator width, the probes are distributed antisymmetrically. Assuming a symmetrical flowfield, this enables measuring both static and pitot pressure at the same location, in other words, at the same distance from the center plane. The wall pressure measurements around the two cross-sections mentioned previously suggest that this assumption is valid as the deviation of measurements on both sides were within $3 \%$. This allows for a quite accurate calculation of horizontal static and pitot pressure and Mach number profiles. Over the isolator height, the values have to be interpolated. This is also done for tests with yaw angle for horizontal profiles. The design of the static pressure probes according to Pinckney [34,35] enables measuring the static pressure close to the tip of the probe, which, however, is Mach number dependent in supersonic flow. Calibration measurements yielded a quadratic correlation for this dependency, shown in Fig. $\underline{8}$, and a calibration factor $K$ was derived according to

$$
K=0.00916 M^{2}-0.00613 M+1.0030
$$

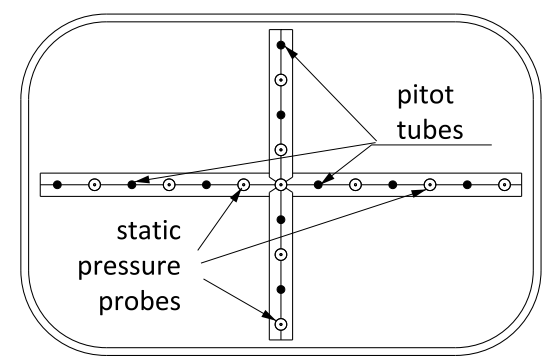

Fig. 7 Distribution of static pressure probes and pitot tubes in the pressure rake.

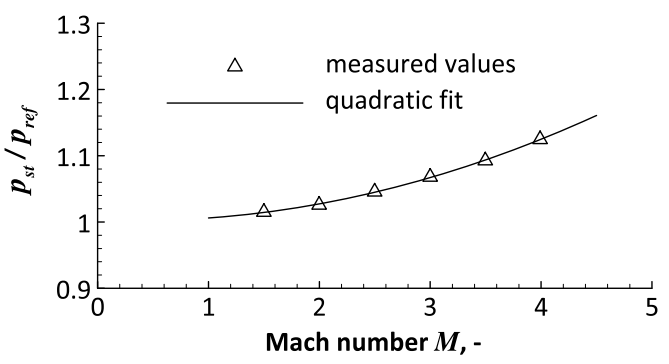

Fig. 8 Mach number dependency of static pressure probes.
A commercial Pressure Systems, Inc., 8400 system [36] with a measurement range of $15 \mathrm{ps} i$ and an accuracy of $0.1 \%$ full scale (FS) or $\pm 103 \mathrm{~Pa}$ was used for pressure measurements. Accuracies for static pressure coefficients were calculated to range from $\pm 3.8-5.6 \%$ with the lower bound for maximimal and the upper bound for minimal pressure levels that occured in the current test series [19]. For the Mach number derivation, the horizontal and vertical parts of the pitot rake have to be regarded separately. As mentioned previously, the pressure rake enables measuring both static and pitot pressure at the same distance from the center plane. Assuming a $\pm 3 \%$ deviation in static pressure on both sides of the center plane due to small asymmetries of the flowfield as seen in the circumferential pressure measurements described previously gives a certainty of the Mach number calculation of about $\pm 2 \%$. For vertical profiles, accuracy is less, as pressure values have to be interpolated between the nearest pressure probes. Assuming a 10\% variation of the interpolated value gives an accuracy of around $\pm 6 \%$ for the Mach number determination [19]. The same is expected for the horizontal Mach number profiles of tests with angle of yaw. In this case, the flowfield is not symmetric, and the pressures also have to be interpolated.

\section{B. Performance Parameters}

Inlet performance is assessed by the static pressure ratio $\Pi_{\mathrm{st}}$ for the compression of the captured airflow and total pressure recovery $\pi_{t}$ for the efficiency of the inlet. These parameters are calculated from the measurements of the pressure rake. The values are first calculated for each measurement location $i$ and then integrated mass-flow averaged. The mass flow is determined from the static pressure and previously calculated Mach number:

$$
\dot{m}_{i}=p_{\mathrm{st}, i} A_{i} M_{i} \sqrt{\left(\frac{\gamma}{R T_{t 0}}\right)\left(1+\frac{\gamma-1}{2} M_{i}^{2}\right)}
$$

Static and total pressure ratios are then derived from Eqs. (4) and (ㅁ).

$$
\begin{gathered}
\Pi_{\mathrm{st}}=\frac{p_{\mathrm{st}, \mathrm{ex}}}{p_{\infty}}=\frac{1}{p_{\infty}} \sum_{i} p_{\mathrm{st}, i} \frac{\dot{m}_{i}}{\dot{m}_{0}} \\
\pi_{t}=\frac{p_{t}}{p_{t 0}}=\frac{1}{p_{t 0}} \sum_{i} p_{t, i} \frac{\dot{m}_{i}}{\dot{m}_{0}}=\frac{1}{p_{t 0}} \sum_{i} p_{\mathrm{st}, i}\left(1+\frac{\gamma-1}{2} M_{i}^{2}\right)^{(\gamma-1) / \gamma} \frac{\dot{m}_{i}}{\dot{m}_{0}}
\end{gathered}
$$

The accuracy of static and total pressure ratios are strongly dependent on the uncertainty of the Mach number derivation from the pressure rake and are estimated to be around \pm 6 and $\pm 10 \%$, respectively.

\section{Mass-Flow Determination}

The throttle used for simulating the backpressure also serves as a mass-flow meter. Assuming one-dimensional flow and sonic condition in the smallest cross-section area $A_{4}$, the mass flow can be calculated with the procedure of Triesch and Krohn [37] from the pressure $p_{3}$ and temperature $T_{3}$ in the settling chamber upstream of the throttle (position 3). The Mach number $M_{3}$ is determined iteratively by 


$$
\frac{A_{3}}{A_{4}}=\frac{1}{M_{3}}\left(\frac{1+\frac{\gamma-1}{2} M_{3}^{2}}{\frac{\gamma+1}{2}}\right)^{(\gamma+1) / 2(\gamma-1)}
$$

From this, the mass flow is calculated with $p_{3}$ and $T_{3}$,

$$
\dot{m}_{3}=p_{3} A_{3} M_{3} \sqrt{\left(\frac{\gamma}{R T_{3}}\right)\left(1+\frac{\gamma-1}{2} M_{3}^{2}\right)}
$$

where $p_{3}$ is taken as the average of four pressure ports located around the settling chamber of the throttle and $T_{3}$ is measured by two thermocouples. The mass capture ratio MCR is determined by

$$
\mathrm{MCR}=\frac{\dot{m}_{\mathrm{ex}}}{\dot{m}_{0}}=\alpha \frac{\dot{m}_{\text {throttle }}}{\dot{m}_{0}}
$$

where $\dot{m}_{0}$ is the mass flow going through the capture area $A_{c}$ of the inlet and $\alpha$ is a calibration factor determined by calibrating the device according to DIN-1952 [38]. In the region of interest, this factor varies in the range $0.99<\alpha<1.02$. The accuracy of this method is about $\pm 3 \%$.

\section{Wall Heat Flux Measurements}

During some experiments, heat fluxes on the external ramp were evaluated by infrared thermography. This not only gives information on heat loads for design aspects like the selection of cooling mechanisms and materials but also allows insight into the flow structure on the surface and the state of the boundary layer. For the calculation of heat fluxes, the timewise development of the surface temperature distribution is recorded with a FLIR Systems ThermaCAM SC-3000 [39]. The recorded surface temperature distribution is used as the boundary condition for calculating the heat fluxes into the wall by evaluating the thermal energy balance of a solid volume:

$$
\rho(T) c(T) \frac{\partial T}{\partial t}=\nabla \cdot(\lambda(T) \nabla T)
$$

Assuming that lateral heat fluxes can be neglected, which is justified by the use of polyether ether ketone (PEEK), which has a very low thermal conductivity, for the measurement surface and accounting for temperature-dependent material properties, this transforms into the nonlinear one-dimensional heat equation normal to the wall,

$$
\frac{\partial T}{\partial t}=a(T) \frac{\partial^{2} T}{\partial n^{2}}+b(T)\left(\frac{\partial T}{\partial n}\right)^{2}
$$

with the thermal diffusivity

$$
a(T)=\frac{\lambda(T)}{\rho(T) c(T)}
$$

and

$$
b(T)=\frac{\frac{\partial \lambda(T)}{\partial T}}{\rho(T) c(T)}
$$

Equation (10) is then solved by an explicit finite difference scheme to calculate the normal temperature gradient inside the wall. From this, the wall heat flux is calculated by the Fourier law:

$$
\dot{q}_{W}=\lambda_{W}(T) \frac{\partial T}{\partial n}
$$

The convective heat flux is then calculated from the heat flux balance on the surface,

$$
\dot{q}_{\mathrm{conv}}=\dot{q}_{W}+\dot{q}_{\mathrm{rad}}
$$

with the radiative heat flux according to the Stefan-Boltzmann law

$$
\dot{q}_{\mathrm{rad}}=\varepsilon \sigma\left(T_{y=0}^{4}-T_{\mathrm{amb}}^{4}\right)
$$

assuming that the ambient temperature stays constant during the test. A more detailed description of this method is given by Henckels and Gruhn [40]. Once the convective heat flux is determined, the dimensionless Stanton number is calculated by Eq. (16), with the recovery temperature defined by Eq. (17) and a recovery factor $r=0.9$. The accuracy of the results is estimated to be within $\pm 5 \%$ for calculated heat fluxes and $\pm 20 \%$ for the Stanton number [20],

$$
\begin{gathered}
S t=\frac{\dot{q}_{\text {conv }}}{\rho_{\infty} u_{\infty} C_{p, \text { air }}\left(T_{\text {rec }}-T_{w}\right)} \\
T_{\text {rec }}=\left(1+r \frac{\gamma-1}{2} M_{\infty}^{2}\right) T_{\infty}
\end{gathered}
$$

\section{Results}

\section{A. Starting Behavior and Critical Internal Contraction}

The movable cowl can be used to determine the critical internal contraction for the self-starting of the inlet by reversing the usual test procedure. At the start of the experiment, the cowl is in its most upstream position $\left(x_{L}=390 \mathrm{~mm}\right)$, the internal contraction is maximized, and the inlet chokes upon the start of the wind tunnel. Then, the cowl is slowly moved back, decreasing the internal contraction until the inlet flow spontaneously starts, as displayed in Fig. $\underline{9}$, which shows schlieren images in combination with the assumed theoretical flow structure based on the work of van Wie [10] and the static pressure distribution on the ramp (red line).

In the first image, at maximum internal contraction, the flow around the inlet is completely subsonic behind a strong detached shock, which is just visible in the upper left corner. The second image shows the situation just before inlet starting. Presumably, a large separation bubble forms on the external ramp, creating fans of shock and expansion waves, which are barely visible in the schlieren image

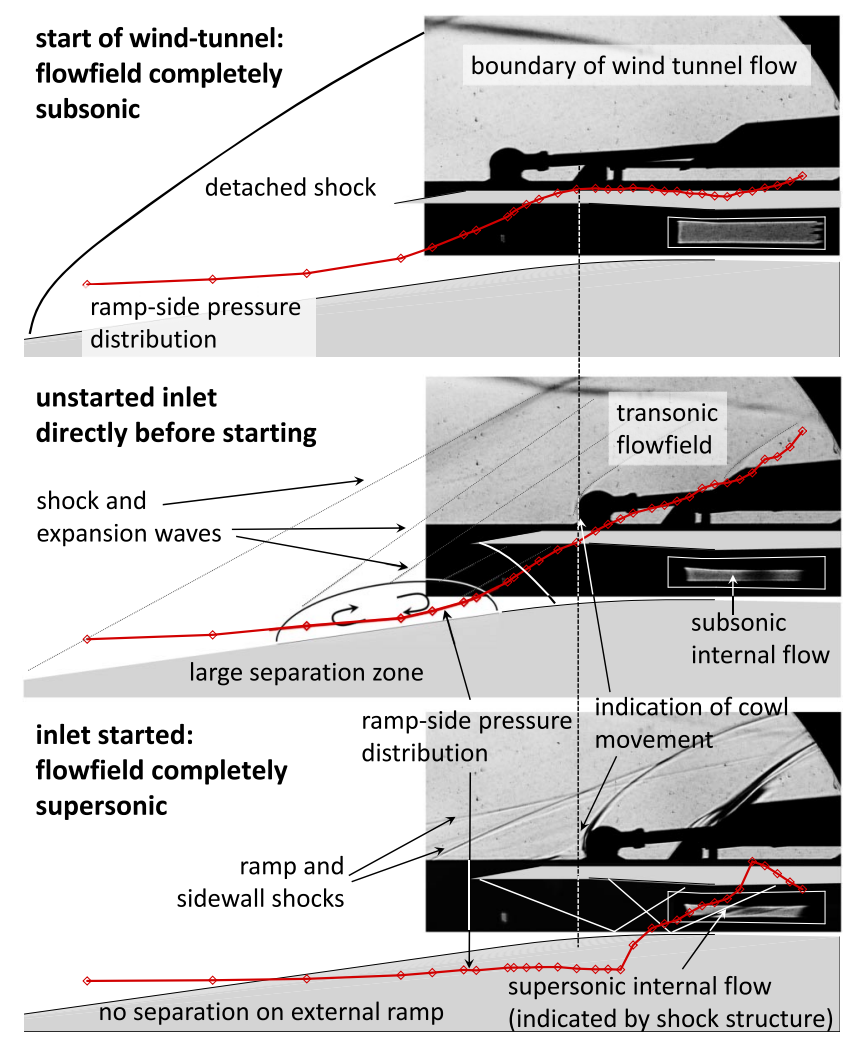

Fig. 9 Flow structure during starting process at condition 1. 


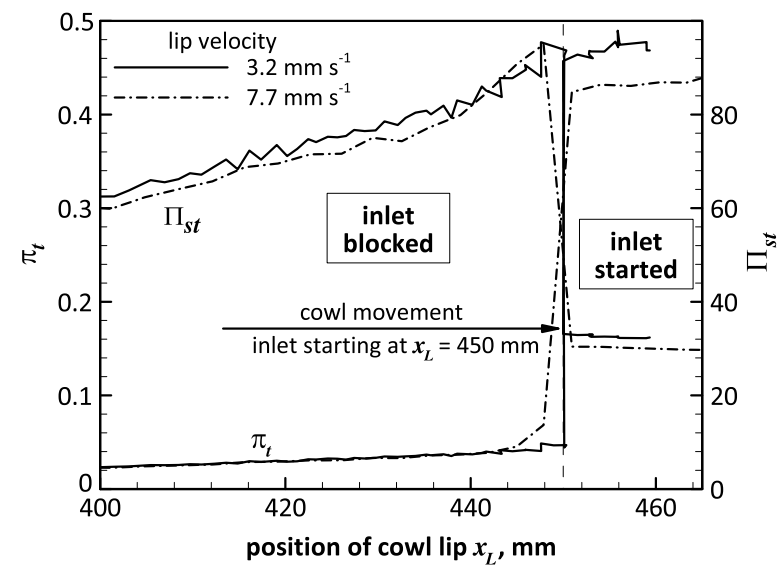

a) Condition 1

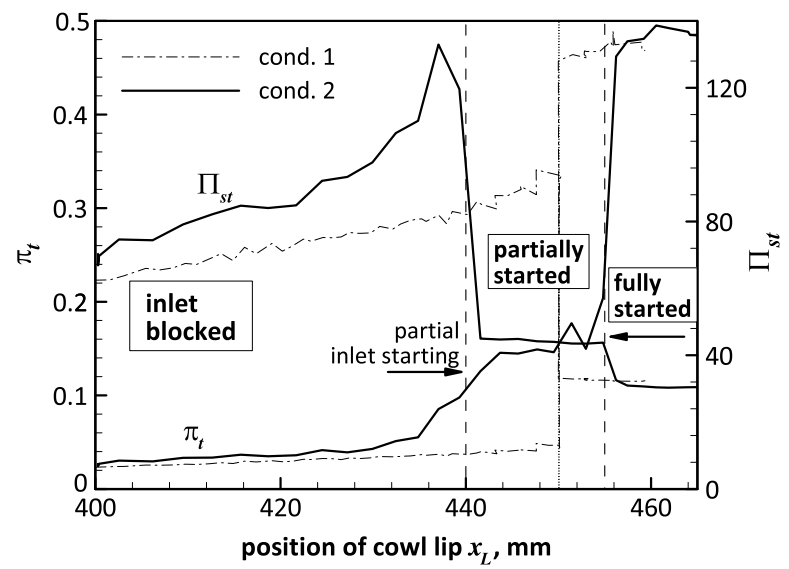

b) Comparison of conditions 1 and 2

Fig. 10 Critical internal contraction for condition 1 (left) and comparison of starting for condition 1 and 2 (right).

but are also indicated by the gradual pressure rise. The internal flow is blocked and subsonic, whereas the spillage mass flow is transonic, as the weak shocks around the cowl suggest (they were highlighted in the image as otherwise they are barely recognizable). The lower picture shows the situation directly after inlet starting. As indicated, the cowl is moved downstream just about $1 \mathrm{~mm}$ compared to the previous image, and the flow suddenly establishes; the separation bubble is swallowed by the inlet, and a supersonic internal flow is established, as the shock structures in the schlieren image (both in the internal and the external flowfield) and the sudden change in the pressure distribution indicate. The sharp drop in static and rise in total pressure in Fig. 10a mark the exact lip position and internal contraction of inlet starting. For condition 1, this occurs at $x_{L}=450 \mathrm{~mm}$, corresponding to a critical internal contraction of $I_{\text {crit }}=1.98$. Furthermore, the comparison of two cowl velocities in this graph implies that the process is not affected by hysteresis.

In comparison, Fig. 10b shows the starting behavior for condition 2, where the inlet does not start spontaneously at one point. First, at $x_{L}=440.5 \mathrm{~mm}$, where the internal contraction of $I=2.2$ is considerably higher than the starting point for condition 1 , the flow partially starts. But only at $x_{L}=456 \mathrm{~mm}$ or $I_{\text {crit, } 2}=1.9$, which is significantly lower than for condition 1 , the flow fully establishes. The starting limits for both conditions are displayed in Fig. 11 in relation to limit by Kantrowitz and Donaldson [24] and isentropic limit; empirical relations by Sun and Zhang [25] and Smart [17], which correlate data from various investigations on 3D inlets; and a semi-empirical approach by Flock and Gülhan [27]. The current results, especially for condition 1 , fit well with these correlations. Further results on starting of this inlet are published in [26].

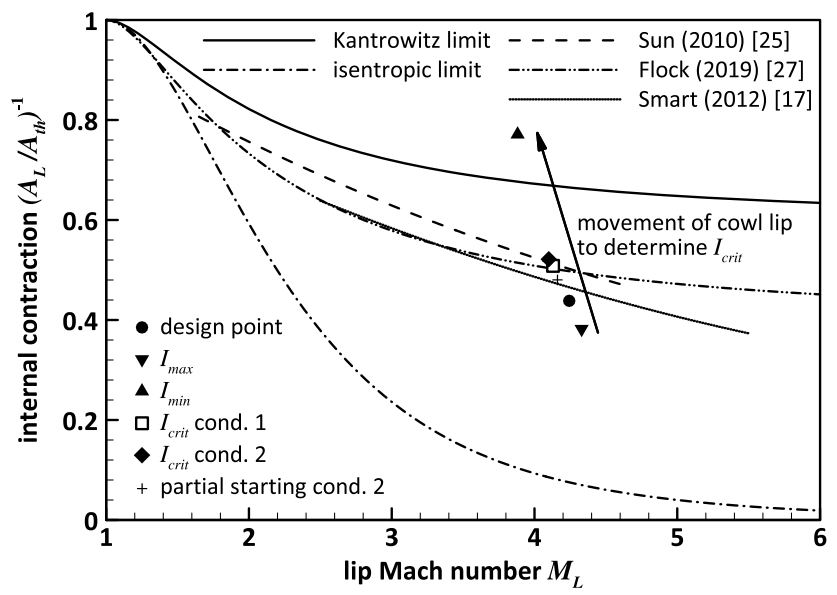

Fig. 11 Comparison of starting limits.

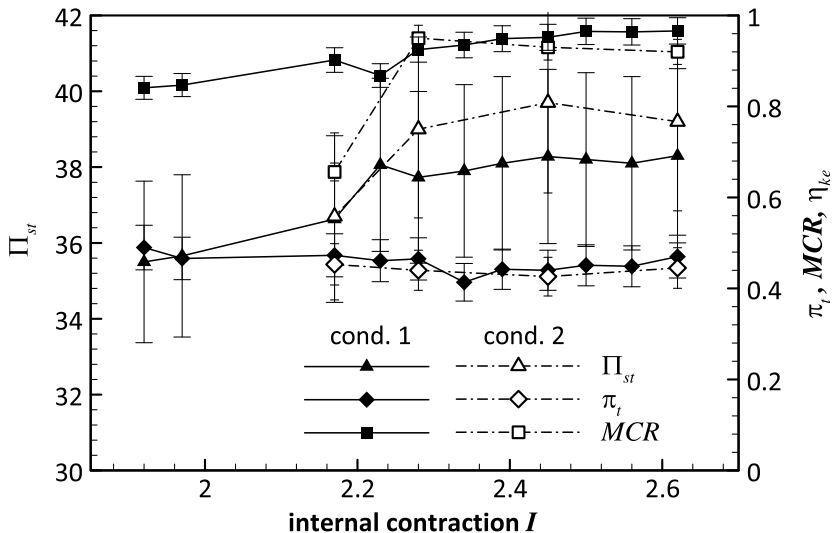

Fig. 12 Performance parameters for varying internal contraction.

\section{B. Performance and Operational Range}

1. Internal Contraction and Reynolds Number

For condition 1 all configurations listed in Table 2 were tested and for condition 2 , only $x_{L}=390,405,420$, and $430 \mathrm{~mm} ; x_{L}=455$ and $452 \mathrm{~mm}$, corresponding to $I=1.97$ and 1.92 , are self-starting cases for which the cowl was set to its target position before the start of the wind tunnel.

Figure 12 summarizes performance parameters over internal contraction for unthrottled flow. Overall, significant changes only occur for those configurations where the ramp shock misses the cowl and spillage is present, in other words, for $I \leq 2.28\left(x_{L} \geq 420 \mathrm{~mm}\right)$. Here, mass capture and consequently the compression ratio drop considerably. Both parameters are lowest for the self-starting configurations with $I=1.97$ and 1.92 . Total pressure recovery increases accordingly. If the ramp shock goes underneath the cowl, changes for all parameters are little, with $\Delta \Pi_{\mathrm{st}} \approx 7.3 \%, \Delta \pi_{t} \approx 6 \%$, and $\Delta \mathrm{MCR} \approx 5.2 \%$. Also, there are only small differences between the two conditions. This is also true for the compression ratio where discrepancies appear to be larger due to the scale of the graph but in fact values are within $3.5 \%$. For condition 1 , performance tends to improve with increasing internal contraction, and the case with $I_{\max }$ shows the highest values. For condition 2, maximum mass capture and compression occur at $I=2.28$ and 2.45 , respectively, but are slightly lower for the case with $I_{\max }$. Total pressure recovery does not have a clear trend for either condition and is rather constant with only small deviations, but values are highest for $I_{\max }$.

The graphs in Fig. 13 show throttle curves for static and total pressure ratios to characterize the operational range for condition 1 . Most notably is that for configurations with $x_{L}<420 \mathrm{~mm}$, for which the ramp shock goes underneath the cowl, inlet unstart occurs much later, at $\Delta \approx 0.14$ and much higher pressure ratios in the range $155 \leq \Pi_{\text {st }} \leq 175$, than for cases where the ramp shock misses the 


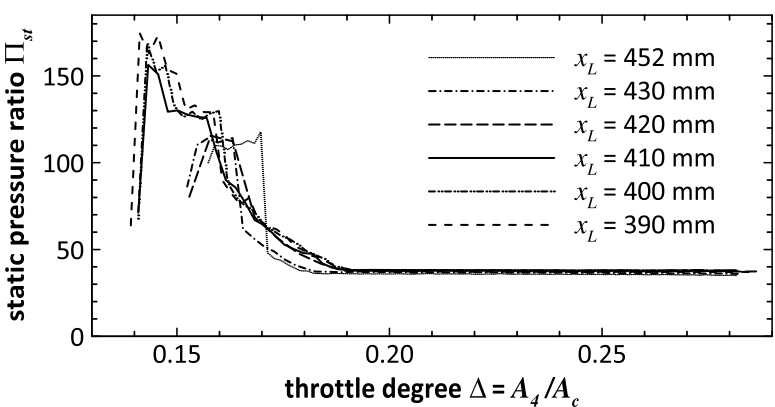

a) Static pressure ratio

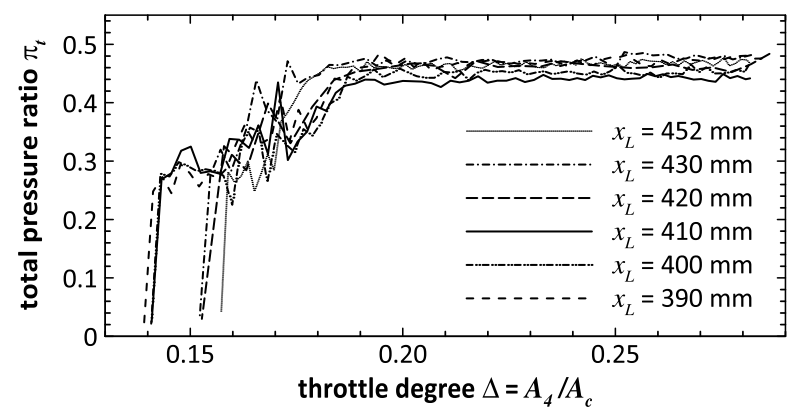

b) Total pressure recovery

Fig. 13 Comparison of compression ratio and total pressure recovery for different internal contractions.

cowl. For these, unstart happens around $\Delta \approx 0.16$ and $\Pi_{\mathrm{st}} \approx 110$. The pressure recovery before inlet unstart is quite similar for all configurations. These observations are also true for other lip positions (see Table 2) that were tested but were omitted in Fig. 13 for better clarity.

The reason for this behavior appears to lie in the different flow topologies of these two cases, in other words, if the ramp goes underneath the cowl or not, which is sketched in Fig. 14. In the first case, there is no separation on the cowl and most likely a laminar boundary layer, whereas in the second case, the shock wave/boundary-layer interaction (SWBLI) of the ramp shock on the cowl surface causes boundary-layer separation. This extends up to the lip so that the corresponding separation shock sits directly at the lip and interacts with the ramp shock. Presumably, the boundary layer downstream is turbulent. Apparently, this flow structure is more stable to high backpressures. In the other case, the rising backpressure probably causes the laminar boundary layer to separate more easily, propagating upstream and causing the cowl shock to jump out of the inlet, which leads to inlet unstart much sooner. For this inlet, the whole internal part seems to act as the isolator, even the converging part upstream of the throat section. Consequently, the inlet operates most stably when the lip is in it most upstream position.

At condition 2, there is no difference between both configurations regarding the throttle degree at which the inlet blocks, but there is still a strong discrepancy in maximum static pressure ratios, although it is less than for condition 1, as can be seen in Fig. 15a. At $x_{L} \leq 420 \mathrm{~mm}$,

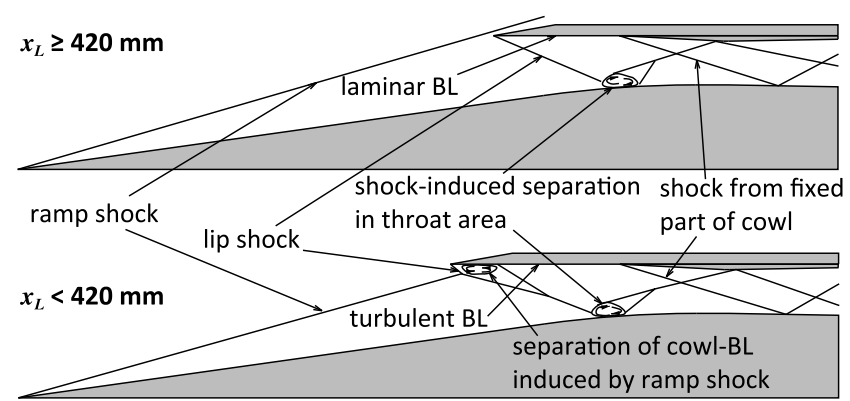

Fig. 14 Centerline flow topology for different lip positions (BL = boundary layer).

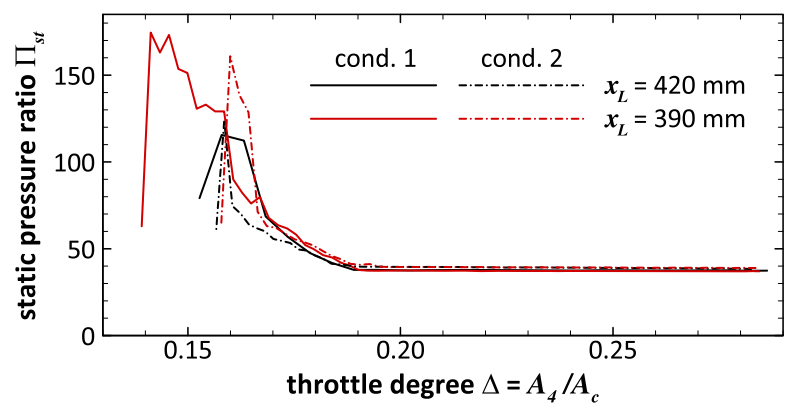

a) Static pressure ratio
$\Pi_{\text {st,max }} \approx 122$, about $6 \%$ more than for condition 1 , while for $x_{L} \leq 390 \mathrm{~mm}$, it is about $9 \%$ lower with $\Pi_{\text {st,max }} \approx 122$. Despite this, the inlet was still found to operate more stably when the ramp shock goes underneath the cowl.

\section{Angle of Attack and Yaw}

To investigate the inlet's suitability for a parabolic flight experiment, rather large angles of attack of $\alpha= \pm 3 \mathrm{deg}$ and $\pm 6 \mathrm{deg}$, with positive $\alpha$ in the clockwise direction, and yaw angles of $\beta=3 \mathrm{deg}$ and 6 deg were considered in the intake characterization. This section shows results for $x_{L}=390 \mathrm{~mm}$ as the configuration with the best performce and most stable operation, which also proved superior at all tested flight angles. Results for other configurations can be found in $[19,29]$.

Figure 16a shows performance parameters for different angles of attack. As expected, the static pressure ratio $\Pi_{\mathrm{st}}$ decreases for positive angle of attack, as the ramp shock becomes weaker, resulting in lower compression. Vice versa, it becomes stronger for negative angles and higher compression. $\Pi_{\text {st }}$ drops by $12 \%$ for $\alpha=3 \mathrm{deg}$ and $35 \%$ for $\alpha=6 \mathrm{deg}$. Mass capture is reduced by about $25 \%$ and almost $50 \%$, respectively, due the smaller capture area. Especially, the latter has to be regarded as critical concerning real flight, as scramjet operation at these conditions will most likely not be possible anymore. For negative angles, as would be expected, static pressure increases with about $+49 \%$ for $\alpha=-3 \mathrm{deg}$ and more than doubles for $\alpha=$ $-6 \operatorname{deg}(+109 \%)$. MCR is slightly reduced for $\alpha=-3$ deg despite the increase in the capture as the ramp shock moves out of the inlet causing some spillage. For $\alpha=-6 \mathrm{deg}$, the further enlargement of the capture area increases MCR by $12 \%$. As MCR always relates to $\alpha=0 \mathrm{deg}$, values of MCR $>1$ are possible. Total pressure recovery declines for positive and negative angles but is only slightly affected.

At the angle of yaw, the stronger compression on the windward sidewall slightly increases the static pressure ratio, by about $3.6 \%$ for $\beta=3 \mathrm{deg}$ and $21.9 \%$ for $\beta=6 \mathrm{deg}$. Total pressure and mass flow are decreased by the stronger sidewall shock and the change of the capture area, but with only little difference in between the two angles, with $\Delta \mathrm{MCR} \approx-12 \%$ and $\Delta \pi_{t 0} \approx-16 \%$.

Figure 17 presents throttle curves for the various angles of attack. The maximum pressure is strongly increased by negative $\alpha$ with $\Pi_{\mathrm{st}}$

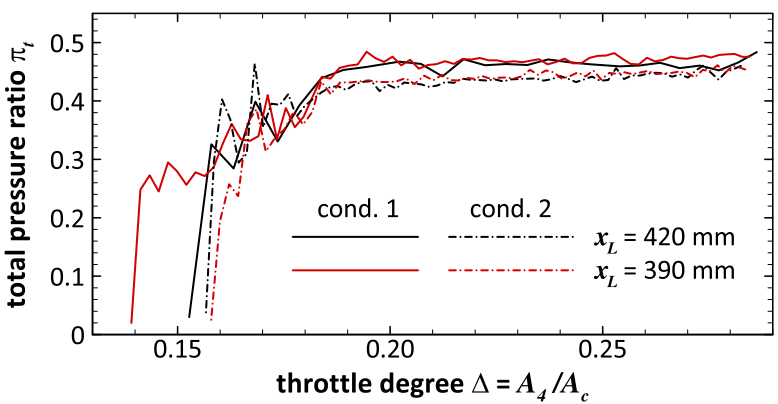

b) Total pressure recovery

Fig. 15 Reynolds number influence on compression ratio and total pressure recovery. 


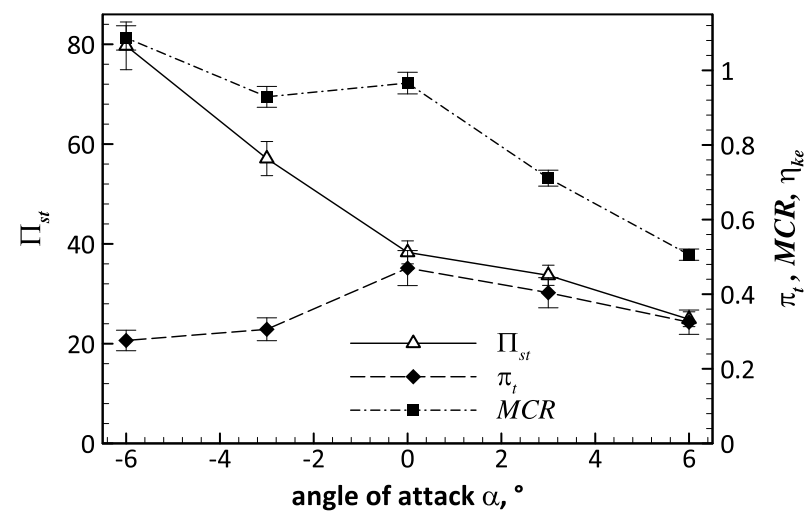

a) Angle of attack

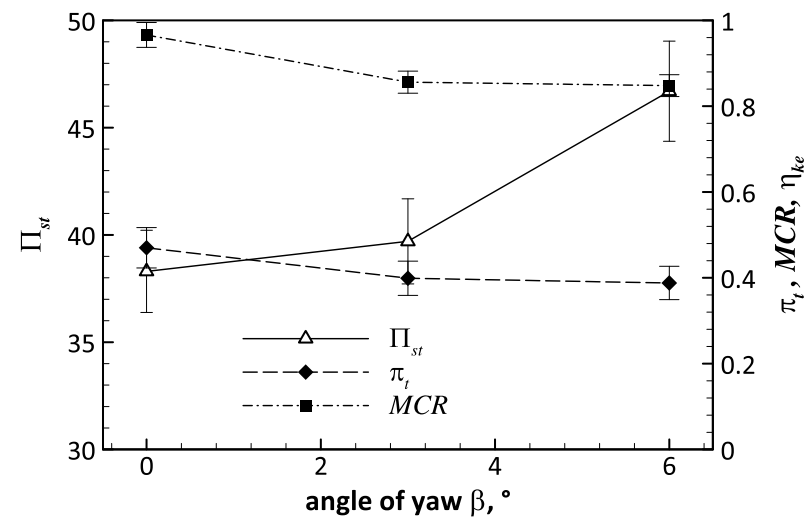

b) Angle of yaw

Fig. 16 Performance parameters for variation of angle of attack and yaw.

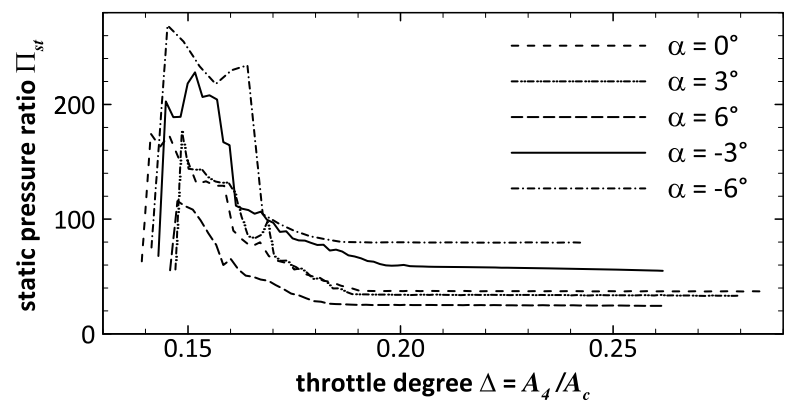

a) Static pressure ratio $\Pi_{s t}$

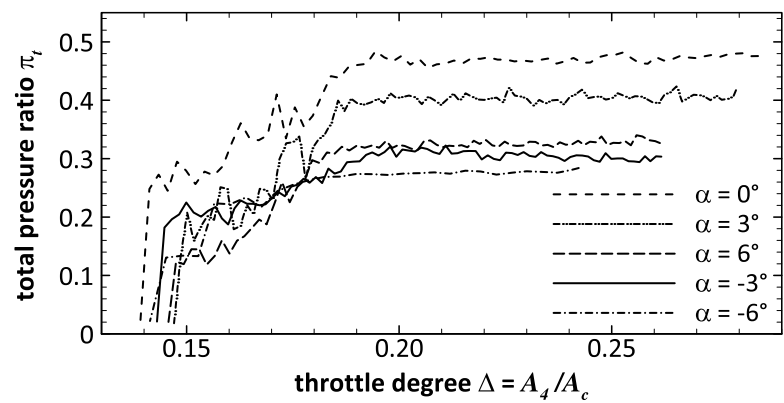

b) Total pressure recovery $\pi_{t 0}$

Fig. 17 Static and total pressure ratios for angle of attack variation.

up almost $60 \%$ to nearly 270 for $\alpha=-6 \mathrm{deg}$. For positive angles, unstart occurs at lower throttle degrees $(\Delta \approx 0.15)$. For $\alpha=3 \mathrm{deg}$, $\Pi_{\text {st,max }}$ is similar to $\alpha=0 \mathrm{deg}$, whereas for $\alpha=-6 \mathrm{deg}$, it is considerably lower (approximately 115). Total pressure decreases faster for all angles and is lower before inlet unstart than for $\alpha=0 \mathrm{deg}$.
The operating range is significantly shortened by yaw angle as the throttle curves in Fig. 18 show, with regular inlet operation stopping around $\Delta \approx 0.16$. For $\bar{\beta}=3 \mathrm{deg}$, unstart occurs at $\Pi_{\text {st, } \max }=145$. For $\beta=6 \mathrm{deg}$, the drop in mass flow and total pressure suggests that inlet buzzing starts around $\Delta \approx 0.16$ and $\Pi_{\text {st, } \max }=155$, although the

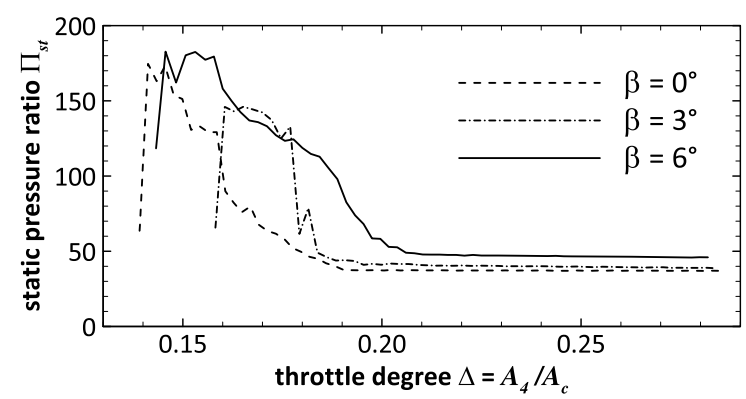

a) Static pressure ratio

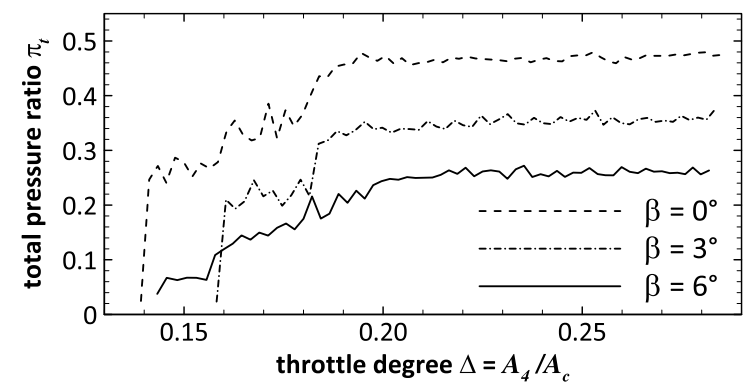

b) Total pressure recovery

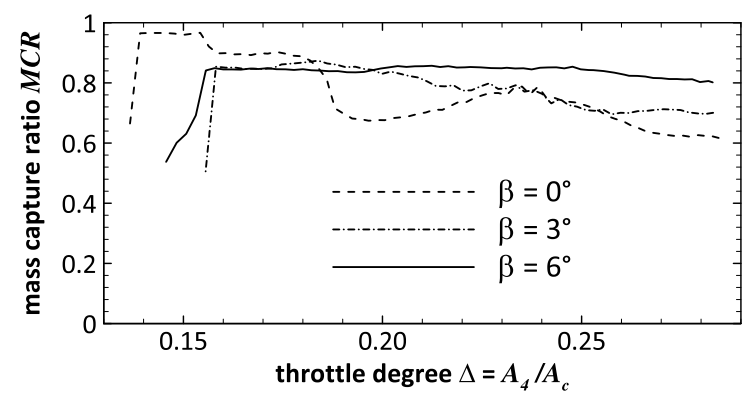

c) Mass capture ratio

Fig. 18 Static and total pressure ratios and mass capture for angle of yaw variation. 
curve for static pressure makes it seem like the inlet would operate similar to the case with $\beta=0 \mathrm{deg}$.

\section{Flowfield Analysis}

\section{Flowfield on External Ramp}

The flow structure on the external ramp was analyzed by IR measurements. Figure 19 shows Stanton number distributions on the PEEK insert in the external ramp. Two streaks with increased heating are visible in each case and presumably are caused by the interaction of the sidewall shocks with the ramp boundary layer and likely vortex formation in these regions. For condition 2, these regions are larger, and $S t$ is considerably higher. The IR measurements alone are not sufficient to conclude on the state of the boundary layer on the external ramp. It is assumed that the flow is laminar in the downstream part and transition takes place in the interaction region of the sidewall shocks with the boundary layer on the ramp. A comparison to complimentary computational fluid dynamics (CFD) in [19] suggests that this might be true for condition 1, while for condition 2, the results were not conclusive. Overall, while the IR measurements give valuable information on aerothermal loads in the external part of the inlet, they proved to be difficult to interpret for insights into the flow structure.

\section{Internal Contraction}

The wall pressure distributions for different lip positions for condition 1 in Fig. 20 reflect the expected flow topology at the center plane. The point of the first strong pressure rise at the lower wall (around $x=0.54-0.56 \mathrm{~m}$ ) marks the location of the interaction with the cowl shock. For $x_{L} \geq 420 \mathrm{~mm}$, this point moves upstream according to the change of the lip position. For $x_{L} \leq 410 \mathrm{~mm}$, this is not the case anymore, and for $x_{L}=400$ and $390 \mathrm{~mm}$, the lines are nearly identical. Thus, when the ramp shock goes underneath the cowl, the lip position does not influence the flow structure. The point of the second pressure rise is where the shock emanating from the edge of the fixed part of the cowl interacts with the ramp. This shock also causes the pressure rise on the upper wall in between the movable and fixed part of the cowl. Farther downstream, pressure drops due to the expansion of the corner where the fixed cowl transitions to the throat and later to the diverging isolator section. The jump in pressure just before the downstream end marks the interaction of the reflected cowl shock with the upper wall. For $x_{L}=410 \mathrm{~mm}$, the shock apparently hits the cowl surface only downstream of the last pressure port. Because of this, only a little pressure rise is recorded, although it is expected to be of the same magnitude than in the other cases.

This is supported by the Mach number profiles in Fig. 21, as the Mach number in the upper half of the isolator shows the location of the cowl shock structure. For $x_{L}=390,400$, and $410 \mathrm{~mm}$, the shock, reflected from the upper wall, passes in between the third and fourth points from the top, causing a strong change in Mach number. For

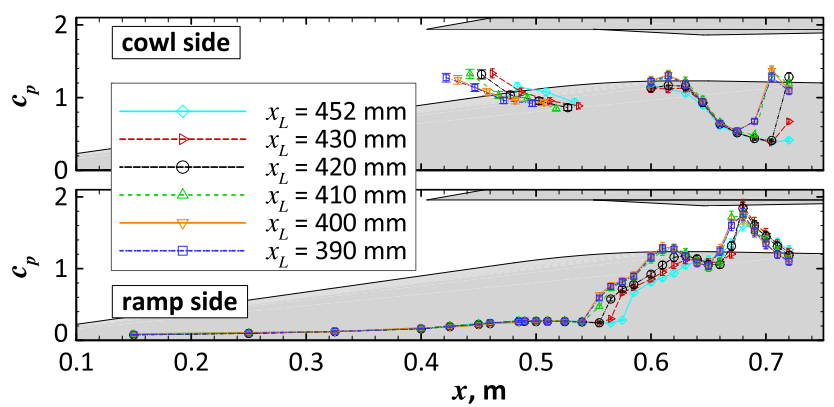

Fig. 20 Wall pressure distribution for different lip positions without backpressure for condition 1 .

$x_{L}=420 \mathrm{~mm}$, it is moved downstream, passing in between the first and second locations, and for $x_{L}=430 \mathrm{~mm}$, it seems to be between the wall and the top pitot probe. In the bottom half, the flow structure is strongly influenced by the shock from the fixed part of the cowl, and thus the influence of the lip position is not as distinct. It is only affected by the shock/shock interaction with the cowl shock and changes in the boundary layer and consequently the shock/boundary-layer interaction. On the horizontal profile, the lip position hardly has any influence, as both shocks pass either above or below the horizontal rake for all configurations. Apart from the points closest to the walls, the flow seems to be quite uniform, especially for $x_{L}=390 \mathrm{~mm}$. There are no sudden changes, which suggests that the sidewall shocks do not propagate into the isolator section.

Figures 22 and 23 show the wall pressure and Mach number distributions for $x_{L}=\overline{390} \mathrm{~mm}$ when the backpressure is increased during the test run. The backpressure propagates upstream through the ramp side boundary layer, inducing a shock train (only a single oblique shock at the beginning), which moves upstream as the pressure is further increased. This can also be observed by the Mach number profile over the isolator height. The backpressure only starts to influence the cowl side pressure distribution when this shock has moved so far upstream that it hits the cowl surface, which occurs at a backpressure ratio of 90 . When it is further increased, the flow structure suddenly changes completely, causing a jump in the pressure ratio to 129 . The shock train now starts at the upper wall, at $x \approx 0.63 \mathrm{~m}$. Downstream of this point, the flow in the upper section is subsonic, and probably the boundary layer separates as well. In the center and lower parts of the isolator, the flow remains supersonic, as Mach number profiles show, and also the wall pressure distribution indicates the structure of the shock train. As the backpressure is further increased, the shock train moves slightly upstream and becomes stronger until at a backpressure ratio of just over 175 inlet unstart occurs.

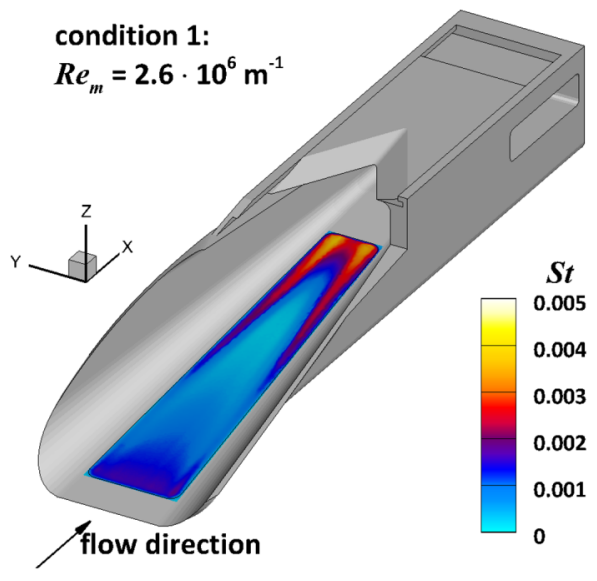

a) cond. $1: R e_{m}=2.610^{6} \mathrm{~m}^{-1}$

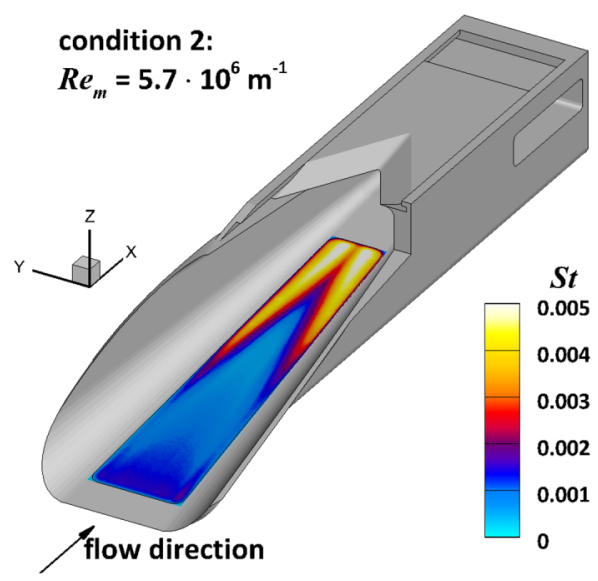

b) cond. 2: $R e_{m}=5.710^{6} \mathrm{~m}^{-1}$

Fig. 19 Stanton number distribution on external ramps from IR measurements. 


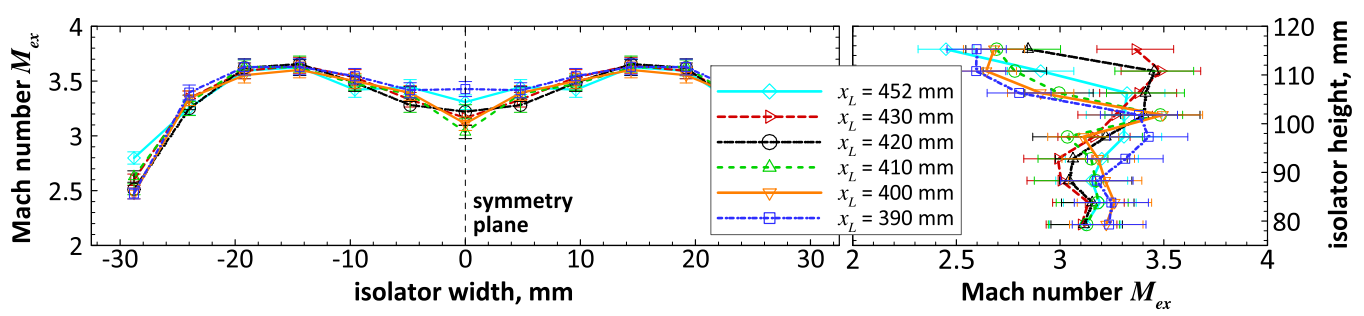

Fig. 21 Horizontal (left) and vertical (right) Mach number profiles for different lip positions.

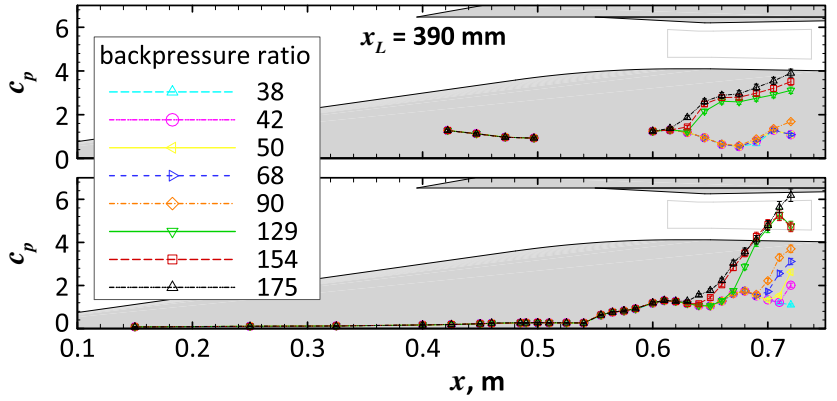

Fig. 22 Wall pressure distribution for different backpressure ratios for $x_{L}=390 \mathrm{~mm}$.

\section{Reynolds Number Variation}

The influence of the Reynolds number on the flowfield is displayed in Figs. 24 and 25 for $x_{L}=390 \mathrm{~mm}$. Higher Re numbers mean thinner boundary layers, which are less likely to separate and to a lesser extent, which causes a slight upstream shift of shock structures. This is expressed by the wall pressure distributions, as pressure rises due to shock/boundary-layer interactions are steeper and restricted to smaller areas. This can be seen in the three interaction regions in the isolator, in other words, the SWBLI on the ramp of the reflected ramp shock $(0.56 \mathrm{~m}<x<0.6 \mathrm{~m})$, on the cowl surface where this shock meets it again $(0.68 \mathrm{~m}<x<0.7 \mathrm{~m})$ and of the shock from the fixed part of the cowl $(0.65 \mathrm{~m}<x<0.68 \mathrm{~m})$ on the ramp. Despite these effects, the general differences in the pressure levels are rather small.

Across the isolator exit, the strongest impact occurs in the central part, both on the vertical and horizontal Mach number profiles; see Fig. 25. Close to the sidewalls, $M_{\mathrm{ex}}$ is higher for condition 2 , while it is significantly lower at the symmetry plane and slightly lower in between. Over the isolator height, $M_{\mathrm{ex}}$ is a bit lower near the top wall but considerably higher for the upper half. At the center, it drops sharply and becomes significantly lower. For the lower third of the vertical profile, $M_{\mathrm{ex}}$ is very similar for both conditions.

\section{Angle of Attack}

The wall pressure is strongly affected by $\alpha$ and is displayed in Fig. 26. The patterns are consequent to the results of the pressure ratio and pressure recovery. For positive $\alpha$, shocks are weaker, resulting in smaller changes and overall lower pressure levels. The opposite is observed for negative angles. Furthermore, the shock angles are

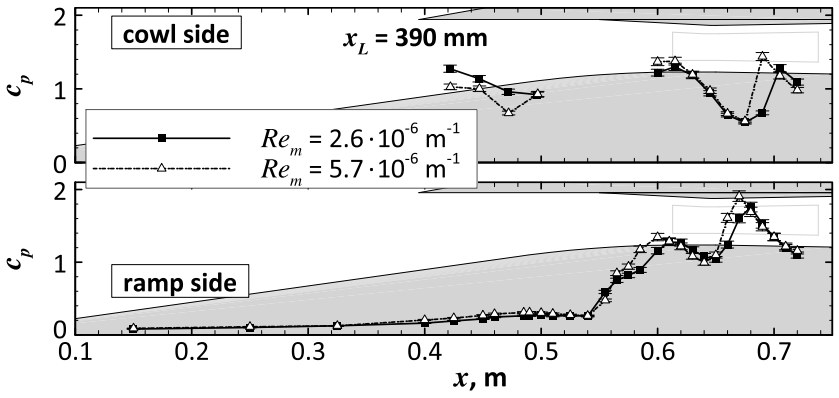

Fig. 24 Wall pressure distribution for different Reynolds numbers for $x_{L}=390 \mathrm{~mm}$.

influenced as well, causing a shift of the shock structures in the streamwise direction.

For $\alpha=-6 \mathrm{deg}$, the pressure peaks at the downstream end of both walls show the effect that the shocks from the cowl lip and the beginning of the fixed part of the cowl are shifted so far upstream that they interact with the respective walls an additional time (as compared to the flow topology sketched in Fig. 14). For other angles, the shift of the shock structure is also visible, but not as distinct. The vertical Mach number profiles in Fig. 27 show the shifts of the shock structures as well, noticeable by the jumps in the Mach number, although it is rather unsafe to conclude where each shock is located. For negative $\alpha$, the Mach number at the isolator exit overall is considerably lower, especially for $\alpha=6 \mathrm{deg}$, and the flow seems to be more uniform over both the spanwise and horizontal profiles.

\section{Angle of Yaw}

The centerline wall pressure distributions for different yaw angles in Fig. 28a generally show an upstream shift of shock structures with increasing $\beta$. The pressure rises on the ramp of the interaction with the cowl shock becomes significantly steeper and higher.

For $\beta=6 \mathrm{deg}$, the start of the pressure rise is also moved upstream to $x=0.5 \mathrm{~m}$. At the fixed part of the cowl, the pressure peak of the interaction with the reflected cowl shock is also moved upstream and, for $\beta=6 \mathrm{deg}$, also is much higher. The shock emanating from the beginning of the fixed part becomes significantly weaker, and consequently the pressure rise due to its interaction with the ramp surface is much less, especially for $\beta=6 \mathrm{deg}$. This is due to the stronger shock strength of the cowl shock structure in combination with the sidewall shocks, which also causes a strong decrease in

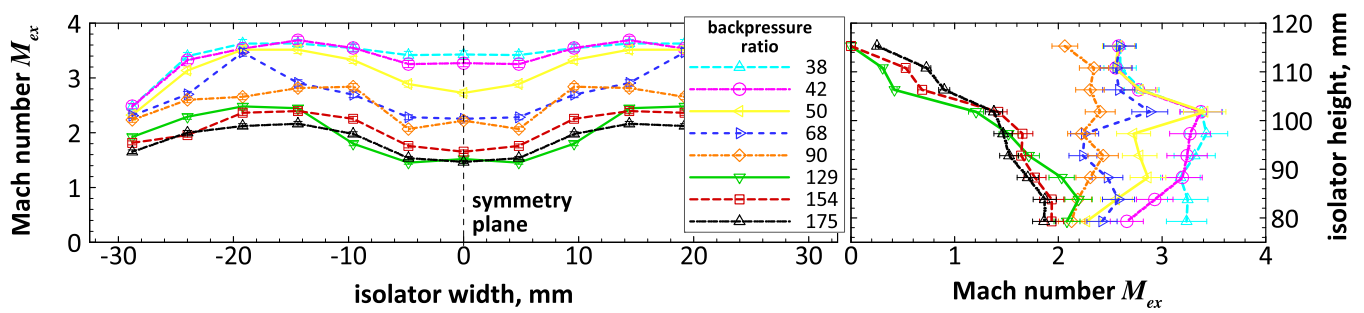

Fig. 23 Mach number profiles for different backpressure ratios for $x_{L}=390 \mathrm{~mm}$. 


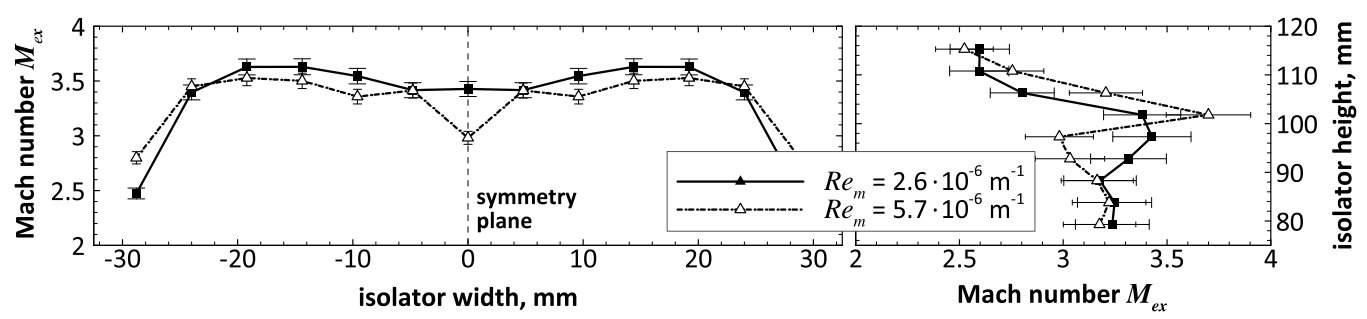

Fig. 25 Mach number profiles for different Reynolds numbers for $x_{L}=390 \mathrm{~mm}$.

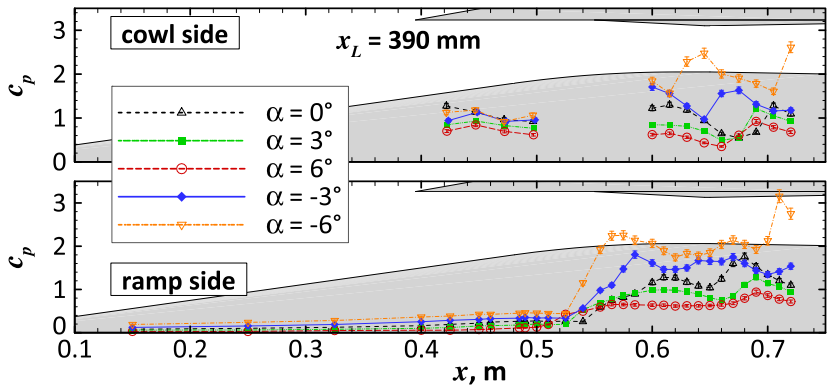

Fig. 26 Static pressure distribution for different angles of attack for $x_{L}=390 \mathrm{~mm}$.
Mach number in the center and lower parts of the isolator, as Fig. 29 shows. Except for the top third of the isolator where $M_{\mathrm{ex}}$ is increased for $\beta=3 \mathrm{deg}$ and about the same for $\beta=0 \mathrm{deg}$ and $6 \mathrm{deg}, M_{\mathrm{ex}}$ continuously drops with increasing $\beta$.

As Fig. 29 also shows, this not only applies to the centerline but also over the width of the isolator, where the Mach number distribution remains quite uniform, especially for $\beta=6 \mathrm{deg}$. As the circumferential pressure profiles in Fig. $28 \mathrm{~b}$ and the pressure curves in Fig. 29 show, there are significant pressure fluctuations introduced to the flow by the yaw angle. Especially in the second cross section, there are large discrepancies between the pressure levels on both sides. The measurements from the pressure rake show that for $\beta=$ 3 deg pressure drops sharply close to the leeward sidewall and then

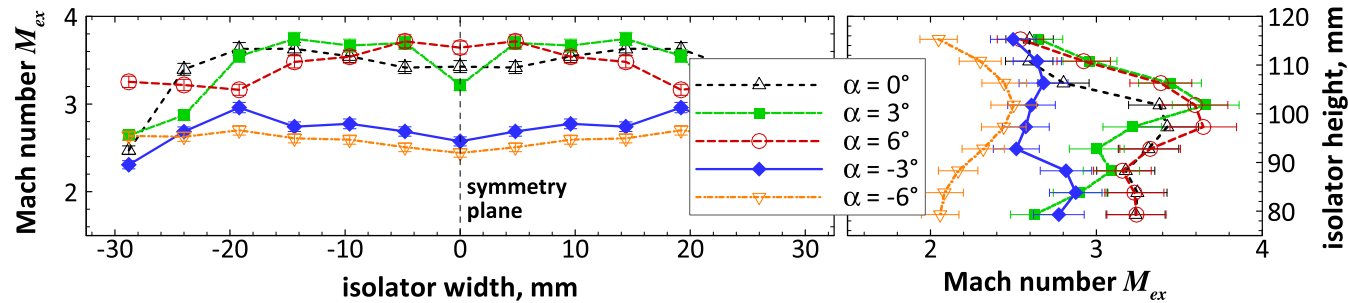

Fig. 27 Mach number distributions for different angles of attack for $x_{L}=390 \mathrm{~mm}$.

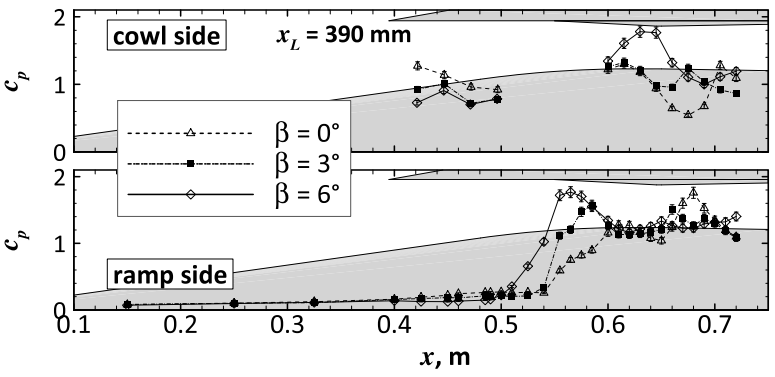

a) Centerline pressure distribution

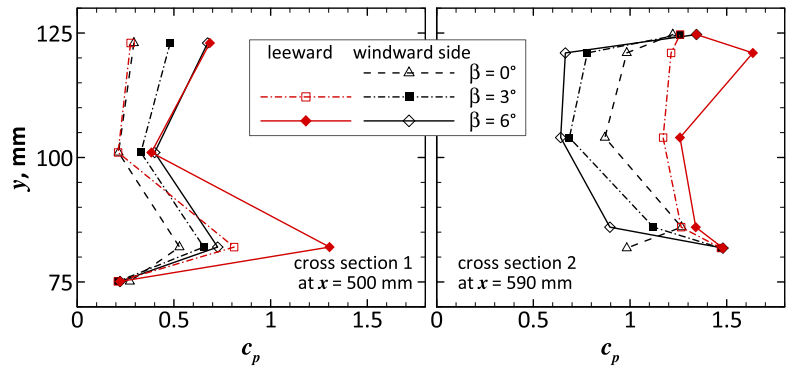

b) Circumferential pressure distribution

Fig. 28 Wall pressure distributions for different angles of yaw.

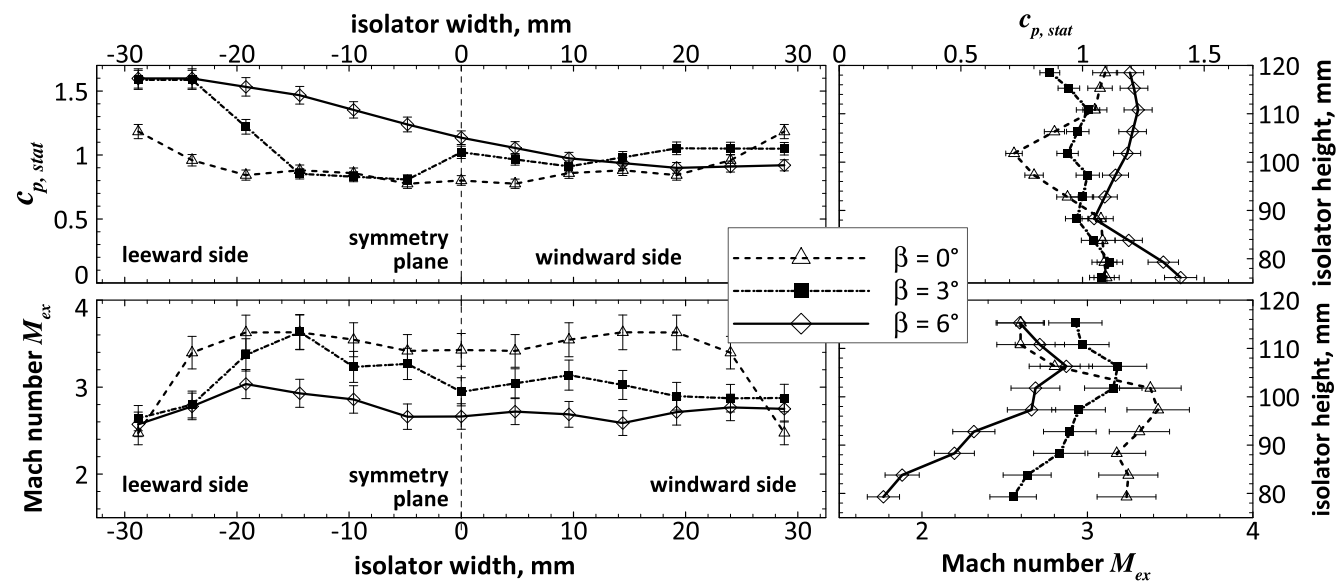

Fig. 29 Static pressure and Mach number profiles for different angles of yaw and $x_{L}=390 \mathrm{~mm}$. 
increases again on the windward side, while for $\beta=6 \mathrm{deg}$, pressure is decreased continuously over the isolator width.

\section{Conclusions}

The measurement campaign conducted in this study shows that the inlet would be well suited for the requirements of the envisaged mission. The starting behavior fit well with results from other 3D inlets. It was also shown that a starting device is necessary as, during testing, the inlet had the best performance and operated most stably at the highest internal contraction ratio at which the inlet was not selfstarting. It made a substantial difference if the ramp shock went underneath the cowl. In contrast to the general expectation, that the strong shock-wave/boundary-layer interaction of the ramp shock on the cowl surface might be problematic, the resulting flow structure in this case was more stable regarding operation at high backpressure ratios. Overall, with increasing internal contraction, which also means a longer internal flowpath, the inlet becomes more resistant to inlet unstart caused by backpressure. An increase of the $R e$ number led to slightly less stable operation and higher heatloads on external ramps. Overall, however, influence on the performance and flowfield was fairly small.

The examination of angle of attack and angle of yaw revealed a strong impact on the intake performance, operation range, and flowfield. Positive angles of attack have to be regarded as critical concerning the reduction in mass flow due to the decreased capture area and, for $\alpha=6 \mathrm{deg}$, a strong reduction of compression and maximum backpressure. It is questionable if supersonic combustion could be sustained at these conditions. High yaw angles led to an early onset of inlet buzzing at significantly lower backpressure ratios. Apart from this, compression for all tested inflow angles, except for $\alpha=6 \mathrm{deg}$, would still be sufficient for stable operation, whereas total pressure recovery was decreased significantly for all cases.

The flowfield was found to be not very sensitive for variation of internal contraction where the change in lip position merely caused streamwise shifts of the flow structure. In contrast to this, angle of attack and yaw had strong influence on the flow structure. Overall, it was observed that the flowfield topology over the height of the isolator exit is more influenced by both angle of attack and angle of yaw than over its width. This has to be carefully considered in the design process of the combustion chamber as it has a strong impact on fuel injection and mixing, and consequently the performance and stability of the combustion process and thus the performance of the overall system.

\section{Acknowledgments}

Funding of this project by the German Research Foundation within the frame of the research training group Graduiertenkolleg 1095/2 is greatly acknowledged.

\section{References}

[1] Heiser, W. H., and Pratt, D. T., Hypersonic Airbreathing Propulsion, 1st ed., AIAA, Washington, D.C., 1994, pp. 2-27, 197-200, 258-263.

[2] Fry, R. S., "A Century of Ramjet Propulsion Technology Evolution," Journal of Propulsion and Power, Vol. 20, No. 1, 2004, pp. 27-58. https://doi.org/10.2514/1.9178

[3] Smart, M. K., Hass, N. E., and Paull, A., "Flight Data Analysis of the HyShot 2 Scramjet Flight Experiment," AIAA Journal, Vol. 44, No. 10, 2006, pp. 2366-2375. https://doi.org/10.2514/1.20661

[4] Dolvin, D. J., "Hypersonic International Flight Research and Experimentation (HIFiRE) - Fundamental Sciences and Technology Development Strategy," AIAA Paper 2008-2581, 2008. https://doi.org/10.2514/6.2008-2581

[5] Mcclinton, C. R., Rausch, V. L., Shaw, R. J., Metha, U., and Naftel, C., "Hyper-X: Foundation for Future Hypersonic Launch Vehicles," Acta Astronautica, Vol. 57, Nos. 2-8, 2005, pp. 614-622. https://doi.org/10.1016/j.actaastro.2005.03.061

[6] Hank, J., Murphy, J., and Mutzman, R., "The X-51A Scramjet Engine Flight Demonstration Program," AIAA Paper 2008-2540, 2008 https://doi.org/10.2514/6.2008-2540
[7] Steelant, J., "LAPCAT: High-Speed Propulsion Technology," Advances on Propulsion Technology for High-Speed Aircraft, NATO RTO (Research Technology Organization), Neuilly-sur-Seine, 2008, pp. $12-1-12-38$. https://doi.org/10.14339/RTO-EN-AVT-150-12-pdf

[8] Weigand, B., and Gaisbauer, U., "An Overview on the Structure and Work of the DFG Research Training Group GRK 1095: "Aero-Thermodynamic Design of a Scramjet Propulsion System"," AIAA Paper 20097276, 2009.

https://doi.org/10.2514/6.2009-7276

[9] Falempin, F., and Serre, L., "LEA Flight Test Program a First Step Towards an Operational Application of High-Speed Airbreathing Propulsion," AIAA Paper 2003-7031, 2003. https://doi.org/10.2514/6.2003-7031

[10] Van Wie, D. M., Scramjet Inlets, Vol. 189, Progress in Astronautics and Aeronautics, AIAA, Reston, VA, 2000, pp. 447-511.

[11] Voland, R. T., Huebner, L. D., and Mcclinton, C. R., "X-43A Hypersonic Vehicle Technology Development," Acta Astronautica, Vol. 59, Nos. 1-5, 2006, pp. 181-191. https://doi.org/10.1016/j.actaastro.2006.02.021

[12] Henckels, A., Gruhn, P., and Gülhan, A., "Design and Experimental Verification of a Scram-Jet Inlet in Frame of ESA's Lapcat Program," Proceedings of the 6th European Symposium on Aerothermodynamics for Space Vehicles, European Space Agency, ESA SP-659, Noordwijk, The Netherlands, Jan. 2009.

[13] Holland, S. D., "Mach 10 Experimental Database of a Three-Dimensional Scramjet Inlet Flow Field," NASA TM-4648, 1995.

[14] Billig, F. S., and Kothari, A. P., "Streamline Tracing: Technique for Designing Hypersonic Vehicles," Journal of Propulsion and Power, Vol. 16, No. 3, 2000, pp. 465-471. https://doi.org/10.2514/2.5591

[15] Smart, M. K., "Design of Three-Dimensional Hypersonic Inlets with Rectangular-to-Elliptical Shape Transition," Journal of Propulsion and Power, Vol. 15, No. 3, 1999, pp. 408-416. https://doi.org/10.2514/2.5459

[16] Riehmer, J., "Aerothermodynamische Analyse eines Scramjet-Flugexperiments," DLR, German Aerospace Center FB-2015-29, Cologne, Germany, 2015.

[17] Smart, M. K., "How Much Compression Should a Scramjet Inlet Do?" AIAA Journal, Vol. 50, №. 3, 2012, pp. 610-619. https://doi.org/10.2514/1.J051281

[18] Banica, M. C., Scheuermann, T., Chun, J., Weigand, B., and Von Wolfersdorf, J. V., "Numerical Study of Supersonic Combustion Processes with Central Strut Injection," Journal of Propulsion and Power, Vol. 26, No. 4, 2010, pp. 869-874.

https://doi.org/10.2514/1.43599

[19] Hohn, O. M., "Auslegung und Charakterisierung eines Dreidimensionalen Scramjet-Einlaufs mit hohem Verdichtungsverhältnis und Variabler Innenkontraktion," DLR, German Aerospace Center FB2014-32, Cologne, Germany, 2014

[20] Häberle, J., and Gülhan, A., "Investigation of Two-Dimensional Scramjet Inlet Flowfield at Mach 7," Journal of Propulsion and Power, Vol. 24 No. 3, 2008, pp. 446-459. https://doi.org/10.2514/1.33545

[21] Hohn, O. M., and Gülhan, A., "Experimental Investigation of Sidewall Compression and Internal Contraction in a Scramjet Inlet," Journal of Propulsion and Power, Vol. 33, No. 2, 2017, pp. 501-513. https://doi.org/10.2514/1.B36054

[22] Goonko, Y. P., Latypov, A. F., Mazhul, I. I., Kharitonov, A. M., Yaroslavtsev, M. I., and Rostand, P., "Structure of Flow over a Hypersonic Inlet with Side Compression Wedges," AIAA Journal, Vol. 41, No. 3, 2003, pp. 436-447.

https://doi.org/10.2514/2.1965

[23] Nguyen, T., Behr, M., Reinartz, B., Hohn, O. M., and Gülhan, A., "Effects of Sidewall Compression and Relaminarization in a Scramjet Inlet," Journal of Propulsion and Power, Vol. 29, No. 3, 2013, pp. 628-638. https://doi.org/10.2514/1.B34740

[24] Kantrowitz, A., and Donaldson, C., "Preliminary Investigation of Supersonic Diffusers," NACA ACR L5D20, 1945.

[25] Sun, B., and Zhang, K.-Y., "Empirical Equation for Self-Starting Limit of Supersonic Inlets," Journal of Propulsion and Power, Vol. 26, No. 4, 2010, pp. 874-875. https://doi.org/10.2514/2.5774

[26] Flock, A. K., and Gülhan, A., "Experimental Investigation of the Starting Behavior of a Three-Dimensional Scramjet Intake," AIAA Journal, Vol. 53, No. 9, 2015, pp. 2686-2693. https://doi.org/10.2514/1.J053786

[27] Flock, A. K., and Gülhan, A., "Modified Kantrowitz Starting Criteria for Mixed Compression Supersonic Intakes," AIAA Journal, Vol. 57, No. 5, 
2019, pp. 2011-2016.

https://doi.org/10.2514/1.J057283

[28] Veillard, X., Tahir, R., Timofeev, E., and Mölder, S., "Limiting Contractions for Starting Simple Ramp-Type Scramjet Intakes with Overboard Spillage," Journal of Propulsion and Power, Vol. 24, No. 5, 2008, pp. 1042-1049. https://doi.org/10.2514/1.34547

[29] Hohn, O. M., and Gülhan, A., "Analysis of a Three-Dimensional, High Pressure Ratio Scramjet Inlet with Variable Internal Contraction," AIAA Paper 2012-5957, Tours, 2012. https://doi.org/10.2514/6.2012-5957

[30] Niezgodka, F.-J., "Der Hyperschallwindkanal H2K des DLR in KölnPorz (Stand 2000)," DLR, German Aerospace Center, DLR Mitteilung 2001-01, 2001.

[31] Hohn, O. M., and Gülhan, A., "Experimental Investigation on the Influence of Yaw Angle on the Inlet Performance at Mach 7," 48th Aerospace Sciences Meeting and Exposition, AIAA Paper 2010-938, 2010. https://doi.org/10.2514/6.2010-938

[32] Kirchner, J., "Data Analysis Toolkit \#5: Uncertainty Analysis and Error Propagation," Berkeley Seismology Lab., University of California, Berkeley, CA, 2001, https://seismo.berkeley.edu/kirchner/eps_120/ Toolkits/Toolkit_05.pdf [retrieved 7 Dec. 2019].

[33] Anderson, J. D., Jr., Fundamentals of Aerodynamics, 4th ed., McGrawHill, New York, 2007, pp. 548-550.
[34] Smith, A. M. O., and Bauer, A. B., "Static-Pressure Probes that are Theoretically Insensitive to Pitch, Yaw and Mach Number," Journal of Fluid Mechanics, Vol. 44, No. 3, 1970, pp. 513-528. https://doi.org/10.1017/S0022112070001969

[35] Pinckney, S. Z., "An Improved Static Probe Design," AIAA Journal, Vol. 12, No. 4, 1974, pp. 562-564. https://doi.org/10.2514/3.49289

[36] Pressure Systems 8400 Users Manual, Ver. 3, Pressure Systems, Inc., Hampton, VA, 1991.

[37] Triesch, K., and Krohn, E.-O., "Verwendung von Kegeldüsen zur Drosselung und Durchsatzmessung bei Überschalleinläufen," DLR, German Aerospace Center, IB 39113-83-A-04, Cologne, Germany, 1984.

[38] DIN 1952-Durchflussmessung mit Blenden, Düsen und Venturirohren in voll durchströmten Rohren mit Kreisquerschnitt, Deutsche Norm (VDI-Durchflussmessregeln), Beuth Verlag, Berlin, 1982.

[39] ThermaCam SC-3000 Users Manual, FLIR Systems, Portland, OR, 1999.

[40] Henckels, A., and Gruhn, P., "Study on Aerothermal Effects of Viscous Shock Interaction in Hypersonic Inlets," Proceedings of the 5th European Symposium on Aerothermodynamics for Space Vehicles, European Space Agency, ESA SP-653, Noordwijk, The Netherlands, Feb. 2005.

R. D. Bowersox Associate Editor 